\title{
Thinking health-related behaviors in a climate change context: a narrative review
}

Guillaume Chevance, $\mathrm{PhD}^{1}$, Ujué Fresán, $\mathrm{PhD}^{1}$, Eric Hekler, $\mathrm{PhD}^{2,3}$, Donald Edmondson, $\mathrm{PhD}^{4}$, Simon J Lloyd, $\mathrm{PhD}^{1}$, Joan Ballester, $\mathrm{PhD}^{1}$, Jill Litt, $\mathrm{PhD}^{1,5}$, Ivana Cvijanovic, $\mathrm{PhD}{ }^{1}$, Vera Araujo-Soares, $\mathrm{PhD}^{6} \&$ Paquito Bernard, $\mathrm{PhD}^{7,8}$

\section{Affiliations}

${ }^{1}$ ISGlobal, Barcelona Institute for Global Health, Barcelona, Spain

${ }^{2}$ Herbert Wertheim School of Public Health and Human Longevity Science, UC San Diego, San Diego, CA, USA

${ }^{3}$ Center for Wireless and Population Health Systems, Qualcomm Institute, UC San Diego, San Diego, CA, USA

${ }^{4}$ Center for Behavioral Cardiovascular Health, Columbia University Irving Medical Center, New York, NY, USA

${ }^{5}$ Environmental Studies, University of Colorado Boulder, CO, USA

${ }^{6}$ Health Technology \& Services Research, University of Twente, The Netherlands

${ }^{7}$ Department of Physical Activity Sciences, Université du Québec à Montréal, Montréal, Québec, Canada

${ }^{8}$ Research Center, University Institute of Mental Health at Montreal, Montréal, Quebec, Canada

\section{Corresponding author}

Guillaume Chevance; Barcelona Institute for Global Health, Carrer del Dr. Aiguader, 88, 08003 Barcelona, Spain; e-mail: guillaume.chevance@isglobal.org 


\section{Abstract}

Background: Human activities have changed the environment so profoundly over the past two centuries that human-induced climate change is now posing serious health-related threats to current and future generations. Rapid action from all scientific fields, including behavioral medicine, is needed to contribute to both mitigation of, and adaption to, climate change. Purpose: This article aims to identify bi-directional associations between climate change impacts and health-related behaviors, as well as a set of key actions for the behavioral medicine community. Methods: We synthesized the existing literature about ( $i$ ) the impacts of rising temperatures, extreme weather events, air pollution, and rising sea level on individual behaviors (e.g., eating behaviors, physical activity, sleep, substance use and preventive care) as well as the structural factors related to these behaviors (e.g., the food system); and (ii) the concurrent positive and negative roles that health-related behaviors can play in mitigation and adaptation to climate change. Results: Based on this literature review, we propose a first conceptual model of climate change and health-related behavior feedback loops. Key actions are proposed, with particular consideration for health equity implications of future behavioral interventions. Actions to bridge the fields of behavioral medicine and climate sciences are also proposed. Conclusions: We contend that climate change is among the most urgent issues facing all scientists and should become a central priority for the behavioral medicine community.

Key words: behavioral health; lifestyle medicine; sustainability, global warming, environmental changes; planetary health 


\section{Introduction}

The purpose of this review is to address the field of behavioral medicine directly, to communicate some of the risks, challenges, and "opportunities" that climate change poses to this field uniquely. A set of key scientific articles about the health consequences of climate change have already been directed to related disciplines in recent years, including urban planning [1], education [2], anthropology [3], economics [4], nutrition [5], psychology [6,7] as well as other medical specialties (e.g., oncology [8], epidemiology [9], psychiatry [10], digital health [11]). Some reflection articles are also emerging in outlets directed at clinicians and practitioners [12-15]. In line with recent goals formulated by the Society of Behavioral Medicine, i.e., "develop research questions at the intersection of climate change, behavior change, and health" [16], the first section of this article presents basic information on climate change and how climate change is shaping our health-related behaviors ${ }^{1}$. The second section illustrates how the promotion of sustainable health behaviors could aid climate change mitigation and adaptation. This article thus summarizes, in a bi-directional way, both the potential impact of various environmental exposures (e.g., heat extremes, air pollution, natural hazards) on behaviors and the key role that some health and pro-environmental behaviors can play in climate change mitigation (e.g., sustainable healthy diet, active transportation) and adaptation (e.g., sleep health to cope with the psychological side effects of extreme weather events).

One of our field's dominant models for understanding and organizing the host of influences on health and health behavior is the socio-ecological model [20] which encompasses individual, interpersonal, organizational, and public policy influences, as well as the natural environment. It is meant to guide understanding of how human behavior interacts with other "levels" of influence. This paper argues that climate change is an all-encompassing influence on health and health behavior, as well as on each level of the socio-ecological model. We also argue that, with ongoing climate change,

\footnotetext{
${ }^{1}$ Climate change is defined in the present article as "a change in the state of the climate that can be identified by changes in the mean and/or the variability of its properties and that persists for an extended period, typically decades or longer" (2). The present manuscript notably focuses on the problems caused by anthropogenic climate change, such as rising temperatures, increasing occurrence and intensity of extreme weather events, air pollution, and rising sea level. Although no clear consensus exists for the definition of health behaviors [17,18], we employed the following one by Gochman (1997): "behavioral patterns and actions that relate to health maintenance, to health restoration and to health improvement" [19]; the word "habit" was removed from the citation to avoid confusion with the psychological construct).
} 
the impact of the natural environment on human health and health behaviors is likely to become increasingly important in the next years. With this review, rather than merely highlight an additional "level" to the social ecological model we propose an initial complex system model, in the form of feedback loops, to illustrate the reciprocal associations between health behaviors and factors related to climate change. While this model is only a rough starting point, we hope it can function as a bridge between the ways behavioral medicine has historically worked and how the field could transition to do its part in climate change mitigation and adaptation.

\section{Climate change: current context and impact on health and health behaviors}

Since the industrial revolution, between 1760-1820, human activities have changed our planet so profoundly that a new unofficial unit of geological time, called the Anthropocene, has been suggested to describe this era of Earth's history, in which the effects of human activity are the dominant influence on climate and ecosystems [21]. We are now living in the 7th decade of the "great acceleration" that began post World War 2, characterized by pronounced, sometimes exponential, and arguably unsustainable growth in several indicators, such as human population, energy consumption, water use, transportation, and telecommunications (see Figure 1, adapted from [1]).

Human activities over the last two centuries, notably uncontrolled greenhouse gas (GHG) emissions and land use changes, have resulted in the sharp warming of our planet. Over the last decade, global surface temperature has increased by $1.09{ }^{\circ} \mathrm{C}\left(0.95-1.20{ }^{\circ} \mathrm{C}\right.$ estimated range $)$, compared to the preindustrial period (1850-1900) [22]. This rapid temperature increase is not uniform around the globe, but is larger over the land $\left(1.59^{\circ} \mathrm{C}\right)$ compared to the oceans $\left(0.88^{\circ} \mathrm{C}\right)$, and is also larger in the high latitudes compared to the tropics. Current global surface temperatures have likely reached levels unobserved over the last 125,000 years [2]. Increase in global surface temperature above 1.5 to $2^{\circ} \mathrm{C}$ is considered extremely dangerous, due to the associated increases in the frequency of extreme weather events, massive biodiversity loss, serious disruptions to food and water safety, and multiple socio-economic consequences [23,24].

For any near term GHG emissions scenario possible under current structural, political, and economic conditions, global surface temperatures are expected to continue to increase until at least 
mid-century [2]. For the most optimistic scenario considered, which assumes rapid decrease in GHG emissions from now on, and net zero carbon dioxide emissions achieved around 2050 (i.e., "Shared Socioeconomic Pathway (SSP)1-1.9"), the end of century global surface temperature is expected to be $1.0-1.8^{\circ} \mathrm{C}$ higher than the $1850-1900$ baseline temperature. For the intermediate scenario (i.e., "SSP2-4.5"), this increase is $2.1-3.5^{\circ} \mathrm{C}$. For the very high GHG emissions scenario ("SSP5-8.5"), the predicted increase in temperature is $3.3-5.7^{\circ} \mathrm{C}$. To put this into perspective, the last time global surface temperature was $2.5^{\circ} \mathrm{C}$ above the $1850-1900$ baseline was more than 3 million years ago [2]. This is profoundly important because human civilization did not develop under those conditions present 3 million years ago, and whether our current civilizations can thrive in such a climate is unknown. The $1.5^{\circ} \mathrm{C}$ global temperature threshold is expected to be exceeded by 2040 under most scenarios (SSP5-8.5, SSP3-7.0 and SSP2-4.5). Clearly, the next few years are the most decisive in human history. In 2017, 15000 scientists from 184 countries signed a manifesto stating that failure to reach these emissions targets could lead to irreversible modifications of Earth's ecosystems, and ultimately, to conditions that would be unhospitable to most human societies, as well as to other species [25].

Although many governments have considered climate change as a national safety and security threat, and a few have initiated some of the necessary transformations required to mitigate its impacts and adapt to it, even the most ambitious actions taken to date are insufficient. Carbon dioxide emissions continue to rise by about $1 \%$ per year worldwide [26]. To illustrate the radical transformation required to adequately address the problem, the COVID-19 pandemic (and the attendant reduction in daily human activity, industrial activity, and economic growth) only resulted in an estimated annual decrease between $-4 \%$ and $-7 \%$ of the worldwide $\mathrm{CO}_{2}$ emissions from 2019 to 2020 [27]. To avoid crossing the $1.5^{\circ} \mathrm{C}$ warming threshold, human societies must reduce $\mathrm{CO}_{2}$ emissions further by the same magnitude year-on-year each year for the next several decades [27]. This makes clear that limiting the worst consequences of climate change requires radical behavioral, economic, and societal transformation simultaneously (i.e., since late 2021, a significant rebound in $\mathrm{CO}_{2}$ emissions has been observed worldwide, showing that the pandemic did not impact the long-term trend in our carbon emissions $[28,29])$. 
There is accumulating evidence that climate change is increasing health risks, including heatrelated illnesses and mortality due to rising ambient temperatures; malnutrition or undernutrition due to reduced food quality and security; freshwater scarcity; together with other indirect effects such as: increased violence due to resource scarcity; propagation of infectious diseases and vector-borne diseases; massive climate-induced population displacement; mental health risk (e.g., with more frequent exposure to extreme weather events); as well as illnesses caused by poor air quality [30-35].

Recognizing these threats, in 2015, the Lancet commission offered the Planetary Health framework to integrate the concept of planetary boundaries into our understanding of public health [30]. The Planetary Boundaries concept identifies planetary limits that should not be crossed because of the likely catastrophic consequences for human health (see [36] and [37] for a graphical view of this framework). Several Planetary Boundaries are directly or very closely linked to climate change: global temperature increase, ocean acidification, biodiversity loss, alteration of the fresh water cycle, land use changes, and modification of atmospheric aerosol loading. The Planetary Health framework proposes that human health and human civilization depend on flourishing natural systems and the wise stewardship of those natural systems, and that overtaking planetary boundaries, particularly in relation to climate change and its impact, will exert increasingly harmful effects on human health globally. Expected impacts have been classified as direct (e.g., heat waves, floods, droughts, sea-level rise, etc), indirect (e.g., population displacement, conflicts) and ecosystems-mediated (e.g., vector-borne diseases, reduced crop yields, reduced nutrients in staple foods). This framework encompasses prior relevant efforts to link planetary and human health, such as Ecohealth, GeoHealth and One Health [38].

In line with the climate related aspects of the Planetary Health framework, the following paragraphs specifically focus on the impacts of climate change on behavioral health. Although there are deep interconnections between each of the potential effects of climate change and associated health behaviors, it is typical in the literature to study each aspect separately, using a reductionist approach. In line with this, the next sections summarize the known relations between specific aspects of climate change and specific health-related behaviors (i.e., impacts of specific climate change factors on specific health-related behaviors). 


\subsection{Rising temperatures and temperature extremes}

Rising temperatures and more frequent or prolonged heat waves are expected to impact eating behaviors, physical activity, sleep, and substance use. These effects, however, are complex to summarize because: (i) their associated behavioral impacts differ by climatic zones; for example, rising temperatures may be perceived as a "positive" development in some colder regions (e.g. more opportunities for physical exercise due to milder temperatures) and negative in already warm regions (less opportunities for physical exercise due to too high temperatures); (ii) they are nonlinear, i.e., rising temperatures could be associated with positive outcomes until a threshold is reached (i.e., a “tipping point”), after which sharp negative effects will become apparent (i.e., limits to human physiological or societal adaptation capacity); and (iii) they are very often studied and presented "in siloes" (i.e., the direct effect of rising temperatures on physical activity, without accounting for second-order effects, e.g., population-displacement, which makes the interpretation of some results challenging when considering the full consequences of rising temperatures).

Regarding global food production and food security, rising temperatures, and water scarcity and salinization (through rising sea levels and sea water infiltration in coastal areas), will negatively impact crop yields and the nutritional quality of vegetables and legumes [39]. For example, iron, zinc, and protein concentrations in wheat, rice, and some legumes will significantly decrease in most places as atmospheric $\mathrm{CO}_{2}$ and temperatures increase [40]. This reduction in nutritional quality could be dramatic in places where dietary diversity is low, and where micronutrient deficiencies are already a problem [41]. Additionally, livestock production, wild fish captures, and aquaculture (i.e., the rearing of aquatic animals or plants for food) will be compromised by climate change (e.g., livestock can be impacted by heat stress; warmer temperatures can make waters more suitable to invasive species [4245]). Altogether, reduction in the quantity and quality of foods produced globally would be a threat for every country, resulting in greater food insecurity globally, since even the wealthiest nations often rely extensively on food imports (for example, see [46] for the UK).

Beyond the food system, however, we are unaware of research demonstrating a clear link between rising temperatures and eating behavior (i.e., food choices) in neither short or long terms. 
Eating behavior is influenced by seasonal variation, so fluctuations in weather and temperatures might influence food choices. However, to our knowledge, there is no strong evidence that the consumption of warm weather-associated products increases during warmer summers. On the other hand, climate change could influence our food choices indirectly. As climate change reduces the production of staple foods, livestock, aquaculture, and wild fish captures (see the previous paragraph and [47]), the resulting food shortage will increase food prices, and price is one of the main drivers of food choices [48]. Similarly, the awareness of the role of the food systems in exacerbating climate change may encourage people to adopt a "low carbon" diet. Indeed, environmental sustainability is one of the main reasons that people adopt and maintain plant-based diets ([49,50]; see also section 2 of the present article).

The impact of climate change on physical activity is complex and shaped by geography. Some studies have demonstrated that warmer temperatures have a positive effect on physical activity in colder countries and/or during winter, up to a threshold around $\sim 30^{\circ} \mathrm{C} / 86^{\circ} \mathrm{F}$ (and depends on other local factors, such as humidity; [51-54]). Conversely, physical activity levels are generally low in countries with extremely warm temperatures [55]. Simulation studies suggest that rising temperatures will have an overall negative impact on physical activity participation, especially those models that account for other indirect effects of global warming on physical activity (see [56,57]). Rising temperatures and exposure to more frequent heat waves could also become a particular threat for outdoor workers in physically demanding jobs (e.g., farmers or construction workers; see [58]). For those outdoor laborers, productivity begins to decline at $20^{\circ} \mathrm{C}$ and progressively decreases as temperatures rise (see [59]; and [60], for estimations of workforce hours in the USA that could be lost due to increase heat in the future). This is particularly problematic for undocumented workers, because they are not protected by extreme heat regulations (see for an example in California [61] or the case of Nepali migrants working in Qatar for the next 2022 FIFA World Cup [62]).

Sleep can also be affected by warmer temperatures. A systematic review found that increases in night time temperatures are likely to amplify sleep disturbances and obstructive sleep apnea, particularly among elderly and low-income populations [63]. In the largest study identified, analyses of sleep measurements from wearable devices, comprising over 7 million nighttime sleep records 
across 68 countries, were linked to local daily meteorological data from 2015 to 2017 [64]. In this study, rising nighttime temperatures was associated with shorter within-person sleep duration. The effect of temperature on sleep loss in this study was larger for residents from lower income countries and older adults, and females were affected more than are males. Providing scale for this estimated relationship, nighttime temperatures registering above $25^{\circ} \mathrm{C}$ reduce individual sleep duration by over 7 minutes compared with 5 to $10^{\circ} \mathrm{C}$ [64].

The effects of rising temperatures on substance use have not yet been well examined [65]. Higher monthly alcohol consumption during periods of warmer temperature was found in a national Swedish study [66]; with the effect thought to be mediated by prolonged daylight. A U-shaped association has been observed between apparent temperature (i.e., index combining ambient temperature, humidity, rain, sunshine, and wind) and the incidence of acute excessive drinking in Shenzhen (China; [67]). In that study, the effect of warmer temperature on alcohol consumption appeared immediately and lasted for about 4 days, with effect modification by age and sex.

\subsection{Extreme weather}

With increasing global temperature, the occurrence and/or strength of specific extreme weather events, hazards and disasters (see for the distinction [68]) are likely to increase in the coming years (see [69] for some mechanisms). These events could have both direct and indirect effects on health behaviors (see [70] for a broader view on the consequences of disasters for public health beyond health behaviors).

In terms of food production and security, it is estimated that the number of extreme weather events that have harmed agricultural production has doubled since 1990, threatening global food security, and acutely impacting low-income countries that have fewer resources to cope with resulting damages [71]. Between 2005 and 2015 such disasters cost the agricultural sectors of developing countries $\$ 96$ billion in damaged or lost crop and livestock production [71]. Although few studies have investigated the specific influence of extreme weather on individual eating behavior, it is likely that post-traumatic stress disorder (PTSD), anxiety, and/or depression after hurricanes may increase risk for unhealthy eating behaviors in some populations (see [72] for a study using Twitter as way to 
capture individuals' eating behaviors before, during, and after a hurricane). Finally, extreme weather events can cause general price increases, both locally and through imports/exports of goods, as the supply chain adjusts to disruptions in availability or transportation, and price impacts eating behavior [49].

Regarding physical activity, extreme weather events (notably hurricanes) have been associated with less physical activity through both direct and indirect pathways [52]. These extreme conditions have a direct effect on physical activity long after the specific weather event has passed, by damaging sport and physical activity facilities, as well as bike paths and pedestrian walkways [73]. It has also been argued that, as extreme weather increases, the costs associated with frequent repairs of such facilities will become an important economic issue in some places [74]. The adverse impact of hazardous weather on physical activity participation also seems to be mediated by traumatic stress reactions. For example, one cross-sectional study highlighted that PTSD symptoms in children exposed to Hurricane Ike (US) was associated with more time spent in sedentary activities and less time engaged in outdoor physical activities [75].

Several studies have estimated the impact of hurricanes on both sleep quality and quantity (see [63] for a systematic review). One quasi-experimental study demonstrated a significant decline in subjective sleep quality pre to post-hurricane among young women with low-incomes [76]. Higher rates of self-reported disrupted sleep were also observed after exposure to floods or wildfires [77,78], particularly for rural residents [79]. In some cases, these effects were mediated by mental health issues such as fear, anxiety, or depression after disasters (see [80] for a review on climate change and mental health).

Associations between extreme weather events and alcohol or tobacco consumption vary in the literature. An increase in alcohol use and binge drinking episodes was observed after hurricanes Katrina and Rita [81-83]. However, no significant changes were found for daily smoking, selfreported nicotine dependence, or smoking initiation episodes in adults who experienced hurricanes [82] or more generally, extreme weather events [84]. Substance use consequences of hurricanes and floods could vary for those with pre-existing substance use disorders, history of traumatic experiences [85] or by gender [79]. Cultural factors might also shape substance use after extreme weather events, 
and should be investigated (e.g., high levels of spirituality in a community can play a buffering effect between extreme weather events and substance use [86]; an increase in alcohol use was observed in the US post-extreme weather events [81-83], while, a decrease has been observed in Japan [87]).

Use of preventive medical care, such as screenings, and medication adherence are also likely to be negatively impacted after extreme weather events. A systematic review concluded that medication adherence was poor at short- and medium-term follow-up measurement periods after extreme weather events (i.e., including climate change related events such as hurricanes, as well as non-climate change related events such as earthquakes) notably due to medication and prescription loss during evacuation [88]. Furthermore, one study found a decrease in preventive care visits, blood glucose monitoring, and foot inspections for adults with diabetes after a major storm and flooding [89]. These consequences are both directly and indirectly linked to a breakdown of healthcare systems as a result of extreme weather events. The natural environment must be kept stable to maintain existing health and other care systems that humans have developed, and that most of us have learned to rely upon to maintain our health and lifespan. Unfortunately, because climate changes are already underway, those systems must adapt to the new challenges posed by climate change to assure their own sustainability [13]. Finally, extreme weather events can disrupt and contaminate water supplies (e.g., via damaged drinking water wells), thus impacting potable water accessibility and consumption [90].

\subsection{Air pollution}

The presence of harmful substances in the air is a major environmental health risk that is intimately tied to climate change (i.e., GHGs are a type of air pollution [91]). In 2021, 9 out of 10 people worldwide breathed polluted air, and exposure to air pollution is estimated to cause 7 million deaths every year, largely from strokes, heart diseases and respiratory diseases [92]. The effect of air pollution on health can be direct (e.g., development of chronic and acute respiratory diseases) or indirect, notably through its effect on health-related behaviors.

Air pollution is associated with higher food insecurity through different pathways [93]. Air pollution can accumulate in the food chain and result in negative health effects for consumers, but it 
may also reduce worker productivity in the food sector, which threatens food supply. With regards to eating behaviors, one study found an association between higher air pollution and greater intake of dietary fat, notably trans-fat in adolescents [94]. This result was observed after controlling for relevant covariates, such as proximity to fast-food restaurants. The authors proposed potential neuro-biological mechanisms that are implicated in self-regulation, such as neuroinflammation, to explain the association between air pollution and eating behaviors.

Systematic reviews indicate that several indicators of air pollution are negatively associated with physical activity levels, including leisure physical activity and active transportation, as well as more sedentary behaviors, with pronounced effects among participants with respiratory conditions (see [52]). For example, one longitudinal study conducted among a large sample of students in Beijing (China), showed that a 1 standard deviation increase in ambient PM2.5 concentration (a marker of air pollution levels) was associated with a reduction of 32 minutes of self-reported moderate to vigorous physical activity per week [95]. Recent studies have also investigated the negative impact of air pollution from wildfires on physical activity in children and adults ([96-98] and see [99] for the complex relationships between wildfires and climate change).

As for sleep, one systematic review showed significant differences in snoring, difficulties in initiating and maintaining sleep, difficulty breathing, and worse apnea among children in high vs low air pollution environments (including studies measuring indoor and outdoor air pollution [100]). Although the mechanisms are not yet clear, recent epidemiological investigations also support a positive association between air pollution and obstructive sleep apnea in adults [101].

To our knowledge, no previous studies have examined whether smoking or alcohol consumption were related to air pollution. Short-term associations between air pollution and substance abuse have been examined in two North American studies; greater air pollution concentration was associated with a significant increase in emergency department visits for substance abuse during the following days [102]. This finding, however, was not replicated in a subsequent study [103]. Note that not only outdoor, but also indoor, air pollution could negatively impact health-related behaviors and health outcomes [104]. Finally, although little mentioned in the present review because they are less directly related to climate change, the interactions between health behaviors and other types of 
pollutants are also extremely relevant (e.g., water [106], soil [107] and noise pollution [108]) but not discussed in detail as the focus of this paper is on climate change.

\subsection{Rising sea level}

Between 150 and 340 million of people could be threatened by rising sea level by 2050 [109]. Asia and Pacific regions are among the most vulnerable [110]. Indeed, rising sea levels increase coastal erosion and exacerbate vulnerability to inundation, which could directly harm infrastructure [111], and accelerate salt water intrusion (i.e., encroachment of salt water into ground water supplies) in coastal areas. This could result in catastrophic risk to food production and freshwater availability [110]. These effects could occur on both long and short timescales (e.g., storm surges can temporarily rise the sea level leading to substantial coastal damages [112]).

In the Kiribati Islands, which are seriously threatened by sea level rise, food security has been identified as a public health priority [113]. Further, excess consumption of sodium from water intake has become a public health issue among costal residents, due to increased risk of hypertension associated with sodium intake [114]. Daily sodium consumption of 5.2 to $16.4 \mathrm{~g}$ has been found in low-lying coastal countries (e.g., Bangladesh), while the daily recommended dose is around $2 \mathrm{~g}$ [115]. Salt water intrusion in soil and rivers threatens access to safe drinking water in those regions [116].

In some places, rising sea level has already devastated whole communities, and the health implications of climate-forced relocation due to sea level rise in indigenous communities have already been seen in the US, Panama, Fiji, Papua New Guinea, Solomon Islands, and Vanuatu [117]. In a recent review, negative impacts of those forced-relocations were observed for: traditional food consumption and malnutrition, sanitation related behaviors (e.g., toilets or latrines use), fresh water consumption, and medication access. One qualitative study conducted in the Solomon Islands reported that living in a zone threatened by rising sea level was associated with mental-health mediated sleep issues [118]. Table 1 summarizes the impacts of climate change on health behaviors. This literature shows that, beyond individual factors, environmental exposures are strong determinants of health behaviors that should be urgently considered in the field of behavioral medicine. 


\section{How can health behaviors influence climate change (for better and worse)?}

As shown in the above section, climate change will increasingly shape our behaviors in the future. In return, our health behaviors could have a significant impact on climate change (see the discussion section below for a critical view of individual and collective actions to limit climate change). This impact can be positive, by participating in activities targeting climate change mitigation and adaptation (e.g., [119]). It could also be negative, via engaging in health behaviors that increase a person's carbon footprint (i.e., the amount of carbon dioxide released into the atmosphere as a result of the activities of a particular individual [120]). Although this section is primarily focused on communicating what is known about the potential role of health behaviors in climate change mitigation and adaptation, we describe the literature so that behavioral medicine researchers will have the necessary information to design interventions that yield "co-benefits" for behavior, health, and climate. This section (and the overall review), however, does not provide information on the most appropriate models, methods, or theoretical approaches to support the design and implementation of behavior change interventions.

\subsection{The role of health behaviors for mitigating climate change}

Mitigation can be defined as proactive efforts to limit climate change [121]. Two specific health-related behaviors have notably been classified as potentially "high-impact" individual actions, because they have a major influence on GHG emissions: reduced meat consumption and active transportation ([7]; high-impact is in contrast to other behaviors such as sleep, which have not been linked as behaviors that could contribute to mitigating climate change).

Reducing meat consumption, notably ruminant meat (e.g., beef), is often mentioned as a high impact pro-environmental behavior. Current meat production is responsible for substantial GHG emissions, and requires significant land and freshwater use [122-124]. A recent systematic review estimated that shifting from a standard diet that includes meat consumption to an ovolactovegetarian diet (i.e., meat- and fish-free, but consumption of eggs and dairy products) or a vegan diet (i.e., total absence of animal-derived foods) would reduce individuals' GHG emissions by an average of 35\% and $49 \%$, respectively [123]. A small amount of meat is compatible with sustainable diets (e.g., all 
together, one serving of red meat per week, 2 servings of white meat or fish, 1 serving of dairies per day and 1,5 eggs per week), but in much lower quantities than that of the current trends [125]. From the perspective of what an individual could do, cutting down meat consumption is the most effective food system strategy for staying within planetary boundaries [126]. Reducing meat consumption, however, does not guarantee lower individual GHG emissions. The overall dietary carbon footprint would depend on the type and amount of meat replaced, and the specific food used as a substitute [127]. For instance, if chicken meat is replaced with cheese, the environmental impact could be even higher [41]. This is because cheese has a relatively high environmental impact. It is higher than some types of meats such as chicken or pork, not only by weight, but also by protein and caloric content (i.e., the production of $1 \mathrm{~kg}$ of cheese requires 5 to 15 liters of milk). Addressing potential rebound effects are thus crucial when promoting healthy and sustainable diets (i.e., rebound effects are also labelled spillover effects in psychology). Specifically, if meat calories are replaced, they need to be replaced with food choices that have a lower environmental footprint. It is also critical to note the importance of context. In high income countries, reducing meat consumption will be key to reduce GHG emissions. In low-income countries, however, an increase in animal product consumption may be needed to reduce malnutrition [128]. Based on this, more research is needed to carefully define truly sustainable dietary choices, given different cultural, regional, and national contexts. In addition, more research is needed to understand the impact of different farming practices, for example, the carbon impact of small-operation family-farms [123].

Active transportation, i.e., riding a bike or walking instead of driving an individual car, can contribute to the reduction of GHG emissions from the transportation system [129-131]. This is particularly critical since land transportation, and notably the use of individual cars, represents an important proportion of GHG emissions worldwide (e.g., 12\% of total EU emissions [132] and 59\% of the transportation sector emissions in the US; the transportation sector accounts for $29 \%$ of all GHG emissions in the US [133]). Estimates of GHG emissions reductions from interventions that promote active transport vary extensively from one study to another. For example, a quasi-experimental study conducted in New Zealand reported only a $1 \%$ reduction in $\mathrm{CO}_{2}$ emissions after three years of an intervention that combined walking and cycling infrastructure development and behavior change 
promotion at the scale of a city [134]. At a smaller scale, a case study conducted in Serbia showed that simple improvements to bicycle parking at a university reduced $\mathrm{CO}_{2}$ emissions associated with students' transportation modes by 50\% in one year, compared to the pre-intervention period ([135]; see [136] for a systematic review on this topic). More studies and intervention targets related to the transportation system are needed to foster the role of active transportation in the reduction of GHG emissions and air pollution. For example, there is likely great opportunity for explicitly targeting short trips where motorized vehicles are not needed, as $\sim 30 \%$ of car journeys in Europe cover distances of less than $3 \mathrm{~km}$ and $50 \%$ cover less than $5 \mathrm{~km}$; these distances can be covered within 15-20 minutes by bicycle [137].

Of all the individual actions that one can initiate to mitigate climate change, reduction of meat consumption and active transport and are the most impactful for reducing individuals' GHG emissions, based on the current available evidence. This is true even in comparison to more widely publicized behaviors such as recycling or use of energy saving appliances [119]. However, physical activity and diet are also among the most difficult behaviors to change, and little evidence exists to suggest that standard behavioral interventions yield lasting behavioral modification $[138,139]$. Studies of individual-level behaviors suggest that the most widespread "environmentally friendly" behaviors actually have low mitigation potential (e.g., recycling) and primarily serve to allow individuals to comfort themselves into believing that their current contributions are sufficient [121]. The scale and urgency of the climate change problem requires that behaviors with a strong potential of carbon footprint reduction (i.e., living car-free when possible or sharing cars, avoiding airplane travel, and eating a plant-based diet) become the main focus of any interventions targeting a meaningful effect on the climate $[140,141]$. Of note, there is some evidence that some behaviors with low mitigation potential, such as recycling, can lead to positive rebound effects for behaviors with higher mitigation potential, if they are incorporated as part of a broader intervention (see [140]). Future research should study the effects of health behavior change interventions with regards to both their impact on individual and planetary health, as well as the influence of dual goal setting, for both personal health and reduced environmental impact (see for example [142] for a review of carbon footprint calculator). 
Although this review does not argue for a particular way of implementing behavior change interventions, established frameworks in the field should be used to guide the development of behavior change interventions and identify mechanisms of co-beneficial behavior change (e.g., NIH Stage Model, MOST, ORBIT Model, SOBC experimental medicine approach, MRC Framework [143146]). In comparison with traditional health behavior change interventions, a dual objective of health and sustainability should now be targeted. In other words, future interventions should target human and planetary health simultaneously. This supposes further collaborations between experts in behavioral medicine and environmental scientists (see the section 4.1 for further details).

\subsection{The role of health behaviors for adapting to climate change}

The term "adaptation" corresponds to reactive responses that strengthen resilience and reduce vulnerability toward climate change consequences or, according to the IPCC, "the process of adjustment to actual or expected climate and its effects". Community-level adaptation examples include building floodwalls to reduce risk of catastrophic sea level rise and strengthening local plans for nursing home evacuation during hurricanes. Previous studies have proposed that promoting particular health behaviors could help individuals and communities become more resilient and less vulnerable to future climate change consequences [7,147].

Physical activity, notably, has been offered as an important factor for population resilience after certain types of extreme weather (see [52] for a review). For instance, Kirkpatrick et al. [148] described how bicycling enthusiasts have been organizing community events in US cities to demonstrate how bicycles may be useful just after flooding or hurricanes. Citizen bicyclists have developed community bike races named "disaster relief trials." The riders use a cargo-bicycle to haul large and fragile items, and must cross water, rough terrain, and physical barriers designed to simulate disaster conditions. These disaster relief trials are developed to improve community resilience and cohesion in case of extreme weather events. Other studies have reported physical education-based programs developed for children post-disaster. For example, a quasi-experimental trial was carried out in Leyte (Philippines), one year after the typhoon Haiyan, to test the effect of a school-based sport intervention on adolescents' self-esteem [149]. The authors discussed the role of physical activity and 
sports for youth mental health post-typhoon (see also [150] for an example of physical activity programs post-hurricanes in the US). Regarding physical activity infrastructure, a cross-sectional study assessed neighborhood rebuilding preferences among New-Orleans residents after Hurricane Katrina in 2006 [151]. Results showed that residents' top neighborhood priority, after reducing crime and disorder, was to rebuild cross-walks and playground areas. Finally, physical activity and sport programs could also help social integration in the context of forced climatic migrations in the next years (see for an example [152]). This last point is crucial. By 2050, in a business-as-usual scenario, 1 to 3 billion people could be exposed to a mean annual temperature $>29^{\circ} \mathrm{C}$, conditions currently found in only $0.8 \%$ of the Earth's land surface [153]. Projections by the World Bank suggest that climate change will push more than 140 million people to migrate within their own country by 2050 , especially in tropical regions [154]. Globally, as many as 200 million to one billion humans may become climate change migrants by 2050 [155]. Physical activity and sports could play a key role in community building in the context of forced migration (see [156] for an example).

Beyond physical activity, adaptation with respect to eating behaviors has also begun in many places. For example, relatively successful examples of rooftop urban agriculture, providing fresh greens with shorter transportation routes and storage time for local markets, exist in urban settings (see for example in New York and Chicago [157] and resulting from the COVID-19 pandemic [158]). There is evidence from Byzantium, World-War II Britain, and the Soviet Union collapse that urban gardens increase resilience in times of crisis [159]. Studies have shown positive effects of involvement in community gardens (defined as green spaces where individuals from more than one family grow food communally or side-by-side) on vegetable consumption, weight management, and well-being among vulnerable populations ([160,161]; see also [162], for an ongoing quasi-experimental trial on the effect of community gardening on several health behaviors). Furthermore, community gardens reduce the urban heat island effect, by introducing shade, cooling the ambient air by evapotranspiration, and reducing heat absorption in urban settings [163]. These types of initiatives (i.e., development or involvement in community gardens) are interesting approaches for prevention of food insecurity, as well as for promotion of physical activity and healthy diet, in urban areas. Thus, they should be considered high-value behavioral levers to be promoted within a behavioral medicine 
field that adopts the planetary health definition (see [164]). Similarly, preventing food waste could also play an important role in the behavioral medicine community's vision for a healthy and equitable society. In high-income nations, more than $30 \%$ of all purchased food is wasted [165].

It has also been proposed that sleep health/hygiene should be included as an integral part of any climate resilient system [63]. Sleep interventions could notably aid individuals coping with the psychological side effects of extreme weather events, forced migrations within and between countries, and rising ambient temperatures [63]).

Finally, some researchers have proposed thinking about adaptation in a more drastic manner (e.g., [166]). This is based on the hypothesis that global disruptive impacts from climate change are inevitable. Thus, the risks of malnutrition, starvation, infectious diseases, and second order effects such as civil conflicts and war at a worldwide scale, including in developed countries $[167,168]$ is already imminent. Envisioning the role of behavioral medicine in such extreme scenarios might be of interest for future research. In the short term this could be done by studying the potential role of behavioral medicine in countries already suffering from immediate forms of societal collapses (see for example [169-171] for the potential relationships between climate change and civil conflicts in Syria). Regardless of the context, behavioral medicine expertise can be key in fostering individual and community resilience.

\subsection{The potential, unintentional, amplification of climate change by health behaviors and the}

\section{field of behavioral medicine, and strategies to avoid it}

Beyond these adaptation and mitigation effects, some health-related behaviors are also amplifying climate change. Some sports represent an important source of individual GHG emissions [52]. Aside from massive professional sporting events, most sport-related emissions are caused by motorized transport that is required to participate in the sport. For example, physical activity-related travel (e.g., driving or flying to practice a specific activity) represented 2.2 to $26 \%$ of the annual carbon footprint of German active adults [120]. Further, and as mentioned previously, individual eating behaviors represent a significant contributor to GHG emissions worldwide (i.e., the total food system contributes to $21-37 \%$ of total anthropogenic GHG emissions; [2]). Eating behaviors have an 
impact on climate change from food production, storage, and packaging, to food processing, distribution, sales, and waste [41]. This impact is independent from a food's nutrition quality, meaning that, in some cases, healthy food could contribute to climate change more than unhealthy food (e.g., [172]). Relatedly, tobacco consumption (in)directly amplifies pollution, as smokers release air pollutants (i.e., 6 trillion smoked cigarettes annually [173]). Further, tobacco-related deforestation has occurred in low- and middle-income countries during the last few decades [174].

For these reasons, definitions of sustainable physical activity and sustainable diet have already been proposed in the literature and, in our opinion, should be adopted as default definitions of the behaviors in behavioral medicine (as the ideal to be reached whenever possible). Central to this shift is a recognition that individual health goals and planetary health goals are inherently, intertwined, based on the above review. Bjørnarå et al. defined sustainable physical activity as "activities that are conducted with sufficient duration, intensity and frequency for promoting health, yet without excessive expenditure of energy for food, transportation, training facilities or equipment. Sustainable physical activities have low environmental impact, and they are culturally and economically acceptable and accessible" [175]. They argued that sustainable physical activity should come with an important investment in active travel, the development of local community physical activity practices, and a reduction of equipment and appliances used in daily tasks (e.g., only exercising in gyms equipped with air conditioning). An 'active pro-environmental behaviors' definition has also been proposed: "behaviors that have a minimum impact on the environment, or even have a positive effect on it, and that are conducted though the practice of outdoor physical activity" [176]. Similarly, sustainable diet has been defined as "diets with low environmental impacts which contribute to food and nutrition security and to healthy life for present and future generations. Sustainable diets are protective and respectful of biodiversity and ecosystems, culturally acceptable, accessible, economically fair and affordable; nutritionally adequate, safe and healthy; while optimizing natural and human resources" [177]. Local, unprocessed, plant based and seasonal foods are usually more sustainable [178]. If the field of behavioral medicine does not actively utilize definitions of health behaviors that account for both the health of individuals and the planet, it is highly plausible that, as a field, we could unintentionally contribute to further exacerbating climate change. 
Extending the potential unintended consequences of the behavioral medicine community's default options, intervention modality choices could also unintentionally exacerbate climate change. Research has documented the carbon footprint of different intervention modalities, such as different modes of delivery for behavioral support for smoking cessation. The respective carbon footprint of text messages, telephone, group counseling, and individual counselling were $0.8,0.9,16.1$, and 16.4 tons of $\mathrm{CO}_{2}$ equivalent for 1000 smokers, respectively [179]. As proposed elsewhere [11], we contend that researchers and clinicians should systematically consider both the short-term and long-term effects on health of individuals, and also the environmental implications of particular behavioral medicine research methods and interventions (see also [180]). To support the field in reducing the risk of unintentionally exacerbating climate change, we suggest that behavioral interventions'

environmental impact should become a key criterion to monitor in early phase work, such as proof-ofconcept and feasibility studies. Further, a more rigorous environmental impact estimation could be conducted prior to broad dissemination of any given approach. To support this, methods for calculating individual and intervention-level GHG emissions must be made widely available.

In conclusion, we contend that there is a real risk that the field of behavioral medicine might unintentionally exacerbate climate change, if it continues with business as usual. As highlighted before, there are real opportunities for the field of behavioral medicine to contribute to advancing approaches to climate change mitigation and adaptation, but they must be judged in relation to our field's overall net contribution to climate change. The capacity of the field of behavioral medicine to positively contribute to climate change mitigation and adaptation is undermined when we conduct our work in a vacuum. Engaging in research without consciously considering unintended consequences on the climate could easily negate our field's positive contributions. Building on the information offered earlier, a new definition of health behaviors is proposed in the next section (section 4.1), as a means to foster a new focus on individually and ecologically healthy behaviors.

\section{Putting it all together: A complex adaptive systems model of the feedback loops between climate change and health behaviors}


Based on the results summarized in the previous sections, different systems, including individual humans and health behaviors, ecosystems, and our planetary climate systems, interact in complex ways. This complexity creates a great challenge for our field to find meaningful ways to contribute to climate change mitigation and adaptation. It also provides opportunities for the development of new models to guide our actions. To support the field in this transition, we offer Figure 2, which summarizes the results of our review of the literature, in the form of an initial complex systems map, with a particular emphasis on postulating hypotheses about dynamic feedback loops between behaviors and factors related to climate change. While this model is only a rough starting point, we hope it can function as a bridge between the ways behavioral medicine has historically worked and how the field could transition to do its part in climate change mitigation and adaptation. Specifically, Figure 2 synthesizes the associations previously described, in the form of a system diagram/map. This Figure visualizes the feedback loops between climate change and health behaviors, highlighting that $i$ ) climate change is shaping health behaviors (section 1 of the present article) and that, in return, $i i$ ) health behaviors might have different impacts on climate change outcomes (section 2 of the present article). Based on our literature review, we proposed that climate change is associated with health behaviors through at least two different pathways (lower left corner of the Figure): direct and indirect (or mediated) effects and in the form of behavioral shocks and secular trends (see the Figure and the literature review for illustrative examples). We propose that health behaviors are associated with climate change through two additional modalities (upper right corner of the Figure): positive versus negative effects, as well as both mitigation and adaptation roles. These different categories (e.g., adaptation and mitigation) being more accurately theorized on a continuum than a true dichotomy.

Associations within climate change outcomes are mapped in the upper left corner of the Figure. Individual health behaviors are represented by lines (except occupational physical activity, which represents a specific case materialized here in dotted line); structural factors influencing individual behaviors such as "physical activity infrastructure", "food quality" and "access to fresh water" are framed outside of the "behavioral cloud" in squares. Although there is substantial evidence that health behaviors co-vary $[181,182]$, the between-behavior associations (lower right corner of the Figure) are not represented here for readability. 
Relevant to the various distinctions made in the Figure 2, our literature review showed that the associations between climate change outcomes and health behaviors could be both uni- and bidirectional: (1) uni-directional associations include, for instance, the association between air pollution and sedentary behaviors (i.e., higher level of air pollution leading to higher level of sedentary behaviors) or the negative association between extreme weather events and sleep (i.e., extreme weather events have an impact on sleep, not the other way around); (2) notable bi-directional associations (i.e., self-reinforcing feedback loops) exist between active transportation and air pollution (i.e., higher level of active transportation is associated with less local air pollution, which in turn might increase active transportation), or between GHG emissions and food quantity and quality (i.e., growing food requires the production of GHG, which negatively impacts food quality). These specific associations are not mapped in the present Figure but could be useful when addressing the complexity between climate change and health behaviors (see section 4.2).

\section{Implications and suggested next steps for the field of behavioral medicine}

To summarize, our review highlights the ways in which climate and health-related behaviors are related. Based on our review, we highlight three areas for future work and consideration for the field of behavioral medicine. First, it is crucial to immediately adapt our definition of health behaviors and practices to account for both individual and planetary health. Second, it is profoundly important to engage meaningfully with issues of equity and health disparities when considering health behaviors together with climate change. Third, there are opportunities for the field, if we collectively decided to consciously move towards increased use of a complex systems paradigm for conducting our work.

\subsection{Updating behavioral medicine definitions using the planetary health concept}

It is urgent for behavioral medicine to actively seek synergies between behavioral medicine and climate research communities. Several fundamental principles of behavioral medicine should facilitate the adoption of a planetary health perspective (see $[183,184]$ ), for a conceptual definition of behavioral medicine). Indeed, behavioral medicine $(i)$ is a highly interdisciplinary field that acknowledges multiple drivers and influences related to health behaviors (i.e., assumes individuals are 
embedded within their larger social and natural contexts); (ii) uses reciprocal determinism to characterize the relationships between contexts and behaviors (i.e., understands that both shape each other); and (iii) is based on seeking fundamental principles about human behaviors, but with recognition that said principles influence and are influenced by cultural and environmental factors. We thus contend that behavioral medicine, as a scientific discipline and community, would benefit from opening more lines of research concerned with planetary health, notably in the context of climate change.

As a first step towards merging traditional behavioral medicine and planetary health approaches, we recommend that the definition of health behavior be revised to include the notions of carbon, water, and ecological footprints as determinants and consequences of health and health behavior broadly, as has already been proposed for physical activity and eating behaviors. We contend that the concept of health equity should be added to this definition, which we will further justify and discuss in the next section. To support merging the fields, we propose an update of Gochman's definition [19]: "health-related behaviors can be defined as actions and patterns of actions within a context that enable human choices that result in reduced or net zero carbon, energy, water, and ecological footprint and (in)directly result in equitable improvement, restoration, and maintenance of health for humans and other living beings' health for current and future generations".

A second, concrete and actionable next step the field of behavioral medicine could take is to actively start to utilize its established frameworks for developing interventions (e.g., NIH Stage Model, ORBIT Model, SOBC experimental medicine approach, MRC Framework [143-146]), selecting intervention components (e.g., Behaviour Change Wheel [185]), implementing behavior change interventions (e.g., RE-AIM [186], intervention mapping [187]), and tools such as published taxonomies and lists of behavior change techniques (e.g., [188]) towards interventions that are explicitly developed to contribute to climate change mitigation and adaptation efforts and aligned with this definition. See table 2 for a summary, and for additional concrete examples of actions the field could take now. 


\subsection{Climate change, behavioral medicine, and health equity}

Climate change raises health equity issues that are important to consider in future behavioral medicine research and behavior change interventions. Within countries, people who are wealthy produce more GHG emissions, while people who are socially-disadvantaged emit less GHG but have less resources to cope with present and future climate change consequences. Indeed, annual incomes are a major determinant of household GHG emissions [189,190]. For example, US households with more than $\$ 100,000$ annual income are responsible for nearly one-third of all households' total carbon footprint in the country, but account for only $22 \%$ of the US population [191]. In parallel, it is expected that people living in socially disadvantaged areas, or with less financial resources, will experience more difficulties coping with the health consequences of climate change [192]. For example, a study conducted in San Francisco showed that residents with low-income, including no private motor transport, used more non-motorized transportation during extreme heat episodes, potentially exposing them to higher risk of heat-related health issues than residents with higher incomes [193]. Further, there is evidence that individuals living in socially-disadvantaged areas are more exposed to environmental pollutants (e.g., air, water, land and noise; which are negatively associated with health behaviors; see for example [194]). The field of behavioral medicine has the knowledge, skills, and capacities to meaningfully contribute to reducing health disparities. A key next step for the field could be to consciously develop interventions that are culturally, contextually, and economically appropriate for historically underserved communities and populations, and that support these communities in adapting to climate change. In contrast, mitigation interventions should primarily target individuals with high incomes, as they are proportionally contributing more to GHG levels.

Between countries, a similar pattern is evident, as low- and middle-income countries are more likely to suffer the adverse consequences of climate change than higher income countries in the short term [195]. This pattern raises health equity issues at a global scale, since the major direct contributors to global warming are mostly from higher income countries [196]. The top $10 \%$ of high-income countries cause $33 \%$ of global GHG emissions, whereas the bottom $50 \%$ are responsible for only $15 \%$ of global emissions [197]. Today, excluding some very specific oil producing countries (e.g., Qatar), 
wealthy Western nations, such as Australia, the US, and Canada have the highest per capita footprint, between 15 and 17 tones of $\mathrm{CO}_{2}$ per person and year. To achieve the goal of the Paris agreement, each individual's carbon footprint must stay below 2 tones of $\mathrm{CO}_{2}$ per year [198]. Per capita emissions cannot be solely explained by fossil fuel infrastructure (e.g., in 2019, 3.6\% of France's energy came from fossil fuels, compared to $20 \%$ in Germany [199]). These estimates seem to demonstrate that Western societies have an ethical and moral responsibility to shift their practices, given their historical and present-day contributions to the problem. It is clear that most of the behavioral changes necessary to mitigate climate change must be made by high-income countries. In parallel, high-income countries must increase their support to low- and middle-income countries, to aid their efforts to cope with the current and future consequences of climate change (see [200]). The field of behavioral medicine could contribute to this by supporting community organizing and policy advocacy efforts that explicitly facilitate meaningful shifts in public opinion and culture in high-income countries.

Health equity issues also arise at the inter-generational level. Major negative consequences resulting from today's GHG emissions will be experienced by today's children and young people who currently have little control over those emissions (i.e., 40 to 50 years from now), not today’s adults [201]. Indeed, there is a temporal delay between most GHG emissions (i.e., notably $\mathrm{CO}_{2}$ ) and ecosystem degradation [2]. In other words, the future health of a child born today, and that of their children, is harmed by our current GHG emissions [202]. Recent study suggests that children born in 2020 will experience a two- to sevenfold increase in extreme events, particularly heat waves, compared with people born in 1960 [203]. If we do not radically limit our emissions, many future generations will be asked to cope with unprecedented challenges. The most consequential decisions today are almost certainly being influenced by intergenerational delay discounting (i.e., countries' focus on short-term vs long-term gains). The field of behavioral medicine, with its knowledge of the psychology of these and other issues, could play a major role in helping to advance intergenerational equity as a guiding principle for motivating more rapid efforts on climate change mitigation and adaptation explicitly designed to support children and future generations [204]. Moreover, highincome countries' current approach to emissions reductions since the Paris Agreement transfers a significant proportion of the mitigation burden to future generations. Future generations will face the 
challenge of coping with increasing climate change-related health impacts, while simultaneously developing a low/no carbon energy system, with fewer resources to do so and in a potentially more unstable (i.e., at the social and ecological levels) world [205]. Given this, the field of behavioral medicine could support effective community organizing and advocacy of current youth, to enable their voice and their power to influence current cultural and political discussions.

Finally, climate change is expected to impact the health of women and men differently, particularly in low- and middle-income countries (see [206]). For example, rising temperatures could substantially worsen the health impacts of menopause, notably hot flashes [207]. Further, climate change has the potential to impact women's health through perturbation in the timing of menarche (i.e., the first occurrence of a woman's menstruation) which, in turn, affects women's risk of diseases (see [208]) for the pathways including impact through food, stress or exposure to environmental pollutions). Men could experience risk of some impacts like suicide and severe depression due to extreme weather events impacting their occupational activities (e.g., droughts in Indian's farmers [209]) differently than women. Based on this, the field of behavioral medicine should consciously monitor and seek to understand and address any disparities that might manifest in relation to sex or gender.

\subsection{Behavioral medicine and climate change under the lens of complexity}

While more difficult, we do suggest, as a final recommendation, that the field of behavioral medicine consciously engage in a paradigm shift towards the increased adoption of a complex systems paradigm to its work. As highlighted in the above review, the full consequences of climate change are unlikely to be understood by studying isolated parts of the system. This is true for both climate science [36] and behavioral science [189]. For example, significant rebound effects (e.g., if cycling is less expensive than car travel, more money is available to spend on a long- distance vacation) and negative rebounds (i.e., if cycling is less carbon intensive than car travel, this may motivate a personal reward as long-distance vacation) could occur for individual behavior change [189]. Such effects would, at best, limit the effectiveness of interventions for carbon footprint reduction, or, at worst, worsen emissions (i.e., increase individual carbon footprint; see for an example in the diet domain [127]). At 
both the individual and global scale, future studies will have to address these issues of multiple interactions, feedback loops, rebound effects, or second order effects, thus justifying the adoption of methods from complexity science (see for the behavioral domain [210] and relevant approaches of multiple health behavior change [211,212]).

Second, adopting a complex adaptive systems approach could help to reconcile some existing simplistic and Manichean debates in both the health and environmental literature. This is notably true when pondering the potential effectiveness of individual, or "bottom-up" versus collective, "topdown", actions to either mitigate climate change or change health behaviors [213]. Clearly, both are needed, and the adoption of a complex adaptive systems approach (and methods) could help us move past this false dichotomy by, for example, considering individuals' behavior change and largescale/political actions as interdependent and mutually influencing, in a bi-directional way over time ([214]; and see [200] for the relevant concept of "spiral of sustainability"). High-impact individual behaviors should be enforced in political contexts that support decarbonation of the industrial system $[198,200,215]$. At the same time, pro-environmental behaviors can spread into, and ultimately shape, socio-ecological niches and social/cultural norms in a bottom-up fashion, thus leading to political and structural changes [216,217]. Relevant to individual-focused approaches, future research is needed on how to amplify the efforts of adults and young people, so that their behavior change is supported and their efforts to influence the pace of broader societal change, from the bottom-up.

Third, a key limitation of the literature on climate change and health behaviors is that few or no studies so far has provided a complete (or partially-complete) picture of the complex interactions between climate change and health behaviors. Instead, specific climate change impacts and climaterelevant behaviors are mainly studied in silos, using a reductionist approach (i.e., studying the isolated part of a system, as opposed to the complex system approach [218]). This siloed approach is particularly problematic when it comes to climate change and human behaviors, because each part of the system interacts with every other part [219]. For example, rising temperatures can be positively associated with physical activity in colder regions, but concurrently associated with stronger precipitation and lower sleep quality, that are, ultimately, both negatively associated with physical activity. Illustrating those complexities, a recent study found that high levels of total and occupational 
physical activity accentuated the negative association between air pollution and insomnia in large sample of Chinese adults; in the context of this study being more active implicated higher exposure to air pollution [220]. For this reason, the proposed system diagram (Figure 2) only represents a first attempt at presenting the existing literature on this topic. In future, when more empirical studies adopt a complex systems perspective, our diagram should be adapted and extended to a form of computational models. Specifically, we mean mathematically specified model, similar to those used by climate scientists, which allows the simultaneous consideration of its components and potential mechanistic/process feedback loops. Such a model could make concrete projections about future scenarios from a complex systems perspective, and might also aid the formulation of causal hypotheses for some of the associations presented in the present review (see for previous attempts to link the field of complexity with behavioral medicine [210,221-224]).

\section{Conclusion}

The study of the interactions between climate change impacts and health behaviors is in its infancy, and the present narrative review invites academics, researchers, and practitioners to seek more synergies between the field of behavioral medicine, planetary health, and the science of climate change. More empirically supported action, with studies supporting those initiatives, building on new consolidated research, are needed from the behavioral medicine community to $(i)$ better cope with the impacts of climate change on health behaviors and (ii) foster the role of sustainable health behaviors in communities' efforts toward climate change mitigation and adaptation. Further research is particularly needed in low- and middle-income settings; indeed, most of the research cited in the present review, notably for the first section, were conducted with participants from high-income countries. Overall, and in the short-term horizon, mitigation efforts should focus on high-income countries (and, withincountries, on wealthy individuals, including academics). Adaptation efforts are particularly needed in countries or populations that are already facing the negative consequences of climate change, and have fewer immediate resources to cope with its effects. To conclude, it is clear that climate change is a risk multiplier of current and future unhealthy behaviors. The current major risk for behavioral medicine is to do "too little, too late" to address climate change. This review has shown that all behaviors which 
accelerate climate change are unhealthy behaviors. The behavioral medicine community must transform, so that our expertise can help future generations live well on a finite planet, because we believe that there is "enough, for all, forever" if we manage the Earth's "life support systems" sustainably $[225,226]$. 


\section{Acknowledgements}

G.C and U.F were supported by the Spanish Ministry of Science and Innovation and State Research Agency through the "Centro de Excelencia Severo Ochoa 2019-2023” Program (CEX2018000806-S), and by the Generalitat de Catalunya through the CERCA Program. I.C. was supported by La Caixa Junior Leader Grant 2020 (Marie Skłodowska-Curie grant agreement No 847648). PB is supported by Université du Québec à Montréal, Institut Universitaire de Santé Mentale de Montréal and by a salary award from the Fonds de recherche du Québec - Santé. We thank Dr Roope Kaaronen (Univeristy of Helsinki) for his feedbacks on an earlier draft. 


\section{References}

1. Hancock T, Bezold C. Thinking about the future of health and cities in the Anthropocene. Cities \& Health. 2020 Jun;1-8.

2. Schwerdtle PN, Maxwell J, Horton G, Bonnamy J. ' 12 tips for teaching environmental sustainability to health professionals.’ Medical Teacher. 2020 Feb;42(2):150-5.

3. Zywert K. Human health and social-ecological systems change: Rethinking health in the Anthropocene. The Anthropocene Review. 2017 Dec;4(3):216-38.

4. Hensher M. Anthropocene Health Economics: Preparing for the Journey or the Destination ? In: Zywert K, Quilley S, editors. Health in the Anthropocene: Living Well on a Finite Planet. University of Toronto Press; 2020.

5. Meyer N, Reguant-Closa A. "Eat as If You Could Save the Planet and Win!" Sustainability Integration into Nutrition for Exercise and Sport. Nutrients. 2017 Apr;9(4).

6. Inauen J, Contzen N, Frick V, Kadel P, Keller J, Kollmann J, et al. Environmental issues are health issues: Making a case and setting an agenda for environmental health psychology. European Psychologist. 2021;tba:tba.

7. Bernard P. Health psychology at the age of Anthropocene. Health Psychology and Behavioral Medicine. 2019 Jan;7(1):193-201.

8. Nogueira LM, Yabroff KR, Bernstein A. Climate change and cancer. CA: A Cancer Journal for Clinicians. 2020;70(4):239-44.

9. Anderson GB, Barnes EA, Bell ML, Dominici F. The Future of Climate Epidemiology: Opportunities for Advancing Health Research in the Context of Climate Change. American Journal of Epidemiology. 2019 May;188(5):866-72.

10. Coverdale J, Balon R, Beresin EV, Brenner AM, Guerrero APS, Louie AK, et al. Climate Change: A Call to Action for the Psychiatric Profession. Academic Psychiatry: The Journal of the American Association of Directors of Psychiatric Residency Training and the Association for Academic Psychiatry. 2018;42(3):317-23.

11. Chevance G, Hekler EB, Efoui-Hess M, Godino J, Golaszewski N, Gualtieri L, et al. Digital health at the age of the Anthropocene. The Lancet Digital Health. 2020 Jun;2(6):e290-1.

12. Last JM. A vision of health in the 21st century: medical response to the greenhouse effect. CMAJ: Canadian Medical Association Journal. 1989 Jun;140(11):1277-9.

13. Hensher M, Zywert K. Can healthcare adapt to a world of tightening ecological constraints? Challenges on the road to a post-growth future. BMJ. 2020 Nov;m4168.

14. Shultz JM, Rechkemmer A, Rai A, McManus KT. Public Health and Mental Health Implications of Environmentally Induced Forced Migration. Disaster Medicine and Public Health Preparedness. 2019 Apr;13(02):116-22.

15. McPherson GR. Becoming hope-free: Parallels between death of individuals and extinction of homo sapiens. Clinical Psychology Forum. 2019 May;2019:8-11.

16. Diefenbach MA, Phillips A, Bullock L. Provocative Questions in Behavioral Medicine and the Acceleration of our Science. Annals of Behavioral Medicine. 2020 Dec;54(12):920-3. 
17. Nudelman G, Shiloh S. Mapping health behaviors: Constructing and validating a common-sense taxonomy of health behaviors. Social Science \& Medicine. 2015 Dec;146:1-10.

18. Conner M, Norman P. Predicting Health Behaviour: Research and Practice with Social Cognition Models. Open University Press; 2005.

19. Gochman DS. Handbook of Health Behavior Research I: Personal and Social Determinants. Springer Science \& Business Media; 1997. 548 p.

20. Sallis, J. F., Owen, N., \& Fisher, E. B. (2008). Ecological models of health behavior. In K. Glanz, B. K. Rimer, \& K. Viswanath (Eds.), Health behavior and health education: Theory, research, and practice (pp. 465-486). San Francisco, CA: Jossey-Bass

21. Steffen W, Broadgate W, Deutsch L, Gaffney O, Ludwig C. The trajectory of the Anthropocene: The Great Acceleration. The Anthropocene Review. 2015 Apr 1;2(1):81-98.

22. IPCC, 2021: Climate Change 2021: The Physical Science Basis. Contribution of Working Group I to the Sixth Assessment Report of the Intergovernmental Panel on Climate Change [MassonDelmotte, V., P. Zhai, A. Pirani, S.L. Connors, C. Péan, S. Berger, N. Caud, Y. Chen, L. Goldfarb, M.I. Gomis, M. Huang, K. Leitzell, E. Lonnoy, J.B.R. Matthews, T.K. Maycock, T. Waterfield, O. Yelekçi, R. Yu, and B. Zhou (eds.)]. Cambridge University Press. In Press.

23. Ripple, Wolf C, Newsome TM, Gregg JW, Lenton TM, Palomo I, et al. World Scientists' Warning of a Climate Emergency 2021. BioScience. 2021 Sep;71(9):894-8.

24. Steffen W, Richardson K, Rockström J, Cornell SE, Fetzer I, Bennett EM, et al. Planetary boundaries: Guiding human development on a changing planet. Science [Internet]. $2015 \mathrm{Feb}$ [cited 2020 Aug 3];347(6223). Available from:

https://science.sciencemag.org/content/347/6223/1259855

25. Ripple, Wolf C, Newsome TM, Galetti M, Alamgir M, Crist E, et al. World Scientists' Warning to Humanity: A Second Notice. BioScience. 2017 Dec;67(12):1026-8.

26. Friedlingstein P, Jones MW, O'Sullivan M, Andrew RM, Hauck J, Peters GP, et al. Global Carbon Budget 2019. Earth System Science Data. 2019 Dec;11(4):1783-838.

27. Le Quéré C, Jackson RB, Jones MW, Smith AJP, Abernethy S, Andrew RM, et al. Temporary reduction in daily global CO 2 emissions during the COVID-19 forced confinement. Nature Climate Change. 2020 Jul;10(7):647-53.

28. Li R, Li S. Carbon emission post-coronavirus: Continual decline or rebound? Structural Change and Economic Dynamics. 2021 Jun 1;57:57-67.

29. After steep drop in early 2020, global carbon dioxide emissions have rebounded strongly - News [Internet]. IEA. [cited 2021 Nov 15]. Available from: https://www.iea.org/news/after-steep-dropin-early-2020-global-carbon-dioxide-emissions-have-rebounded-strongly

30. Whitmee S, Haines A, Beyrer C, Boltz F, Capon AG, Dias BF de S, et al. Safeguarding human health in the Anthropocene epoch: report of The Rockefeller Foundation-Lancet Commission on planetary health. The Lancet. 2015 Nov;386(10007):1973-2028.

31. Hsiang SM, Burke M. Climate, conflict, and social stability: what does the evidence say? Climatic Change. 2014 Mar;123(1):39-55.

32. Ebi KL, Frumkin H, Hess JJ. Protecting and promoting population health in the context of climate and other global environmental changes. Anthropocene. 2017 Sep 1;19:1-12. 
33. McMichael AJ. Globalization, Climate Change, and Human Health. New England Journal of Medicine. 2013 Apr;368(14):1335-43.

34. Watts N, Amann M, Arnell N, Ayeb-Karlsson S, Belesova K, Boykoff M, et al. The 2019 report of The Lancet Countdown on health and climate change: ensuring that the health of a child born today is not defined by a changing climate. The Lancet. 2019 Nov 16;394(10211):1836-78.

35. Romanello M, McGushin A, Napoli CD, Drummond P, Hughes N, Jamart L, et al. The 2021 report of the Lancet Countdown on health and climate change: code red for a healthy future. The Lancet. 2021 Oct 30;398(10311):1619-62.

36. Steffen W, Rockström J, Richardson K, Lenton TM, Folke C, Liverman D, et al. Trajectories of the Earth System in the Anthropocene. PNAS. 2018 Aug 14;115(33):8252-9.

37. The nine planetary boundaries [Internet]. [cited 2021 Nov 15]. Available from: https://www.stockholmresilience.org/research/planetary-boundaries/the-nine-planetaryboundaries.html

38. Del Bianco A, Mallery D, Paudel K, Bunch M. The exploration of socioecological approaches and indicators in the Anthropocene. In: Health in the Anthropocene: Living Well on a Finite Planet. University of Toronto Press; 2020.

39. Scheelbeek PFD, Bird FA, Tuomisto HL, Green R, Harris FB, Joy EJM, et al. Effect of environmental changes on vegetable and legume yields and nutritional quality. Proceedings of the National Academy of Sciences. 2018 Jun;115(26):6804-9.

40. Myers SS, Zanobetti A, Kloog I, Huybers P, Leakey ADB, Bloom AJ, et al. Increasing CO 2 threatens human nutrition. Nature. 2014 Jun;510(7503):139-42.

41. Macdiarmid JI, Whybrow S. Nutrition from a climate change perspective. The Proceedings of the Nutrition Society. 2019;78(3):380-7.

42. US EPA O. Climate Impacts on Agriculture and Food Supply [Internet]. [cited 2021 Nov 15]. Available from: https://19january2017snapshot.epa.gov/climate-impacts/climate-impactsagriculture-and-food-supply

43. Maulu S, Hasimuna OJ, Haambiya LH, Monde C, Musuka CG, Makorwa TH, et al. Climate Change Effects on Aquaculture Production: Sustainability Implications, Mitigation, and Adaptations. Frontiers in Sustainable Food Systems. 2021;5:70.

44. Rojas-Downing MM, Nejadhashemi AP, Harrigan T, Woznicki SA. Climate change and livestock: Impacts, adaptation, and mitigation. Climate Risk Management. 2017 Jan 1;16:145-63.

45. Cheung WWL, Lam VWY, Sarmiento JL, Kearney K, Watson R, Zeller D, et al. Large-scale redistribution of maximum fisheries catch potential in the global ocean under climate change. Global Change Biology. 2010 Jan;16(1):24-35.

46. Macdiarmid JI, Clark H, Whybrow S, Ruiter H de, McNeill G. Assessing national nutrition security: The UK reliance on imports to meet population energy and nutrient recommendations. PLOS ONE. 2018 Feb;13(2):e0192649.

47. Zhao C, Liu B, Piao S, Wang X, Lobell DB, Huang Y, et al. Temperature increase reduces global yields of major crops in four independent estimates. PNAS. 2017 Aug 29;114(35):9326-31.

48. Chen P-J, Antonelli M. Conceptual Models of Food Choice: Influential Factors Related to Foods, Individual Differences, and Society. Foods. 2020 Dec;9(12):1898. 
49. Fresán U, Errendal S, Craig WJ. Influence of the Socio-Cultural Environment and External Factors in Following Plant-Based Diets. Sustainability. 2020 Jan;12(21):9093.

50. Janssen M, Busch C, Rödiger M, Hamm U. Motives of consumers following a vegan diet and their attitudes towards animal agriculture. Appetite. 2016 Oct;105:643-51.

51. Heaney AK, Carrión D, Burkart K, Lesk C, Jack D. Climate Change and Physical Activity: Estimated Impacts of Ambient Temperatures on Bikeshare Usage in New York City. Environmental Health Perspectives. 2019;127(3):37002.

52. Bernard, Chevance G, Kingsbury C, Baillot A, Romain AJ, Molinier V, et al. Climate change, physical activity and sport: a systematic review. Sports Medicine. 2021;5(1):1041-59.

53. Obradovich N, Fowler JH. Climate change may alter human physical activity patterns. Nature Human Behaviour. 2017;1(5).

54. Turrisi TB, Bittel KM, West AB, Hojjatinia S, Hojjatinia S, Mama SK, et al. Seasons, weather, and device-measured movement behaviors: a scoping review from 2006 to 2020. International Journal of Behavioral Nutrition and Physical Activity. 2021 Feb;18(1):24.

55. Al-Hazzaa HM. Physical inactivity in Saudi Arabia revisited: A systematic review of inactivity prevalence and perceived barriers to active living. International Journal of Health Sciences. 2018;12(6):50-64.

56. Liu J, Yang L, Zhou H, Wang S. Impact of climate change on hiking: quantitative evidence through big data mining. Current Issues in Tourism. 2020 Dec;1-17.

57. An R, Shen J, Li Y, Bandaru S. Projecting the Influence of Global Warming on Physical Activity Patterns: a Systematic Review. Current Obesity Reports [Internet]. 2020 Oct [cited 2020 Oct 19]; Available from: http://link.springer.com/10.1007/s13679-020-00406-w

58. Habibi P, Moradi G, Moradi A, Heydari A. The impacts of climate change on occupational heat strain in outdoor workers: A systematic review. Urban Climate. 2021 Mar;36:100770.

59. Ebi KL, Capon A, Berry P, Broderick C, Dear R de, Havenith G, et al. Hot weather and heat extremes: health risks. The Lancet. 2021 Aug 21;398(10301):698-708.

60. Zhang Y, Shindell DT. Costs from labor losses due to extreme heat in the USA attributable to climate change. Climatic Change. 2021;164(3):1-18.

61. Horton SB. They Leave Their Kidneys in the Fields: Illness, Injury, and Illegality among U.S. Farmworkers. 2016. 312 p.

62. Pradhan B, Kjellstrom T, Atar D, Sharma P, Kayastha B, Bhandari G, et al. Heat Stress Impacts on Cardiac Mortality in Nepali Migrant Workers in Qatar. Cardiology. 2019;143(1):37-48.

63. Rifkin DI, Long MW, Perry MJ. Climate change and sleep: A systematic review of the literature and conceptual framework. Sleep Med Rev. 2018 Dec;42:3-9.

64. Minor K, Bjerre-Nielsen A, Jonasdottir SS, Lehmann S, Obradovich N. Ambient heat and human sleep. arXiv:201107161 [cs, econ, q-fin] [Internet]. 2020 Nov 13 [cited 2021 Nov 15]; Available from: http://arxiv.org/abs/2011.07161

65. Etcheverry PE, Agnew CR, Newberry MA. Weather and the Prediction of Daily Cigarette Smoking. Journal of Smoking Cessation. 2012 Jun;7(1):37-40. 
66. Hagström H, Widman L, Seth E von. Association between temperature, sunlight hours and alcohol consumption. PLOS ONE. 2019 Sep;14(9):e0223312.

67. Liu X, Wen Y, Zhang K, Duan Y, Li H, Yan S, et al. Examining the association between apparent temperature and incidence of acute excessive drinking in Shenzhen, China. Science of The Total Environment. 2020 Nov;741:140302.

68. Lavell, Oppenheimer, Diop, Hess, Lempert, Li, et al. Climate change: newdimensions in disaster risk, exposure, vulnerability, and resilience. In: Managing the Risks of Extreme Events and Disasters toAdvance Climate Change Adaptation. Cambridge University Press. New-York; 2012. p. 24-65.

69. Cai W, Borlace S, Lengaigne M, van Rensch P, Collins M, Vecchi G, et al. Increasing frequency of extreme El Niño events due to greenhouse warming. Nature Climate Change. 2014 Feb;4(2):111-6.

70. Giorgadze T, Maisuradze I, Japaridze A, Utiashvili Z, Abesadze G. Disasters and their consequences for public health. Georgian Med News. 2011 May;(194):59-63.

71. Food and Agriculture Organization. The impact of disasters and crises on agriculture and food security: 2021 [Internet].2021 [cited 2021 Nov 15]. Available from: http://www.fao.org/documents/card/en/c/cb3673en

72. Turner-McGrievy G, Karami A, Monroe C, Brandt HM. Dietary pattern recognition on Twitter: a case example of before, during, and after four natural disasters. Natural Hazards. 2020 Aug;103(1):1035-49.

73. Inoue Y, Havard CT. Sport and disaster relief: a content analysis. Disaster Prevention and Management: An International Journal. 2015 Jun;24(3):355-68.

74. Orr M, Inoue Y. Sport versus climate: Introducing the climate vulnerability of sport organizations framework. Sport Management Review. 2019 Aug;22(4):452-63.

75. Lai BS, La Greca AM, Llabre MM. Children's sedentary activity after hurricane exposure. Psychological Trauma: Theory, Research, Practice, and Policy. 2014;6(3):280-9.

76. Wu ZH, Stevens RG, Tennen H, North CS, Grady JJ, Holzer C. Sleep Quality Among LowIncome Young Women in Southeast Texas Predicts Changes in Perceived Stress Through Hurricane Ike. Sleep. 2015 Jul;38(7):1121-8.

77. Alderman K, Turner LR, Tong S. Assessment of the Health Impacts of the 2011 Summer Floods in Brisbane. Disaster Medicine and Public Health Preparedness. 2013 Aug;7(4):380-6.

78. Psarros C, Theleritis C, Economou M, Tzavara C, Kioulos KT, Mantonakis L, et al. Insomnia and PTSD one month after wildfires: evidence for an independent role of the "fear of imminent death.” International Journal of Psychiatry in Clinical Practice. 2017 Apr;21(2):137-41.

79. Tu Y. The Impact of a Natural Disaster on Individuals' Health-Related Behaviors in China. 2020 [cited 2020 Sep 1]; Available from: http://ruor.uottawa.ca/handle/10393/40638

80. Berry HL, Waite TD, Dear KBG, Capon AG, Murray V. The case for systems thinking about climate change and mental health. Nature Clim Change. 2018 Apr;8(4):282-90.

81. Ma C, Smith TE. Increased alcohol use after Hurricane Ike: The roles of perceived social cohesion and social control. Social Science \& Medicine. 2017 Oct;190:29-37. 
82. Beaudoin CE. Hurricane Katrina: addictive behavior trends and predictors. Public Health Reports (Washington, DC: 1974). 2011 Jun;126(3):400-9.

83. Cerdá M, Tracy M, Galea S. A prospective population based study of changes in alcohol use and binge drinking after a mass traumatic event. Drug and Alcohol Dependence. 2011 May;115(12):1-8.

84. Bell SA, Choi H, Langa KM, Iwashyna TJ. Health Risk Behaviors after Disaster Exposure Among Older Adults. Prehospital and Disaster Medicine. 2019 Feb;34(1):95-7.

85. Mukherjee S, Canterberry M, Yore JB, Ledford EC, Carton TW. Assessing the Relationship Between Mental Distress and Tobacco Use in Post-Katrina and Rita Louisiana. Substance Use \& Misuse. 2017 Aug;52(10):1275-82.

86. Castaldelli-Maia JM, Bhugra D. Investigating the interlinkages of alcohol use and misuse, spirituality and culture - Insights from a systematic review. International Review of Psychiatry. 2014 Jun 1;26(3):352-67.

87. Shimizu S, Aso K, Noda T, Ryukei S, Kochi Y, Yamamoto N. Natural disasters and alcohol consumption in a cultural context: the Great Hanshin Earthquake in Japan. Addiction. 2000 Apr;95(4):529-36.

88. Ochi S, Hodgson S, Landeg O, Mayner L, Murray V. Disaster-Driven Evacuation and Medication Loss: a Systematic Literature Review. PLoS Currents [Internet]. 2014 Jul [cited 2020 Aug 14];6. Available from: https://www.ncbi.nlm.nih.gov/pmc/articles/PMC4169391/

89. Saulnier DD, Brolin Ribacke K, von Schreeb J. No Calm After the Storm: A Systematic Review of Human Health Following Flood and Storm Disasters. Prehospital and Disaster Medicine. 2017 Oct;32(5):568-79.

90. Use Safe Water After a Natural Disaster or Emergency | Natural Disasters and Severe Weather | CDC [Internet]. 2021 [cited 2021 Nov 15]. Available from: https://www.cdc.gov/disasters/foodwater/safe-water.html

91. Orru H, Ebi KL, Forsberg B. The Interplay of Climate Change and Air Pollution on Health. Current Environmental Health Reports. 2017;4(4):504-13.

92. WHO global air quality guidelines: particulate matter (PM2.5 and PM10), ozone, nitrogen dioxide, sulfur dioxide and carbon monoxide [Internet]. [cited 2021 Nov 15]. Available from: https://www.who.int/publications-detail-redirect/9789240034228

93. Sun F, Dai Y, Yu X. Air pollution, food production and food security: A review from the perspective of food system. Journal of Integrative Agriculture. 2017 Dec;16(12):2945-62.

94. Chen Z, Herting MM, Chatzi L, Belcher BR, Alderete TL, McConnell R, et al. Regional and traffic-related air pollutants are associated with higher consumption of fast food and trans fat among adolescents. The American Journal of Clinical Nutrition. 2019 Jan;109(1):99-108.

95. Yu H, Yu M, Gordon SP, Zhang R. The association between ambient fine particulate air pollution and physical activity: a cohort study of university students living in Beijing. International Journal of Behavioral Nutrition and Physical Activity. 2017 Dec;14(1):136.

96. Rosenthal DG, Vittinghoff E, Tison GH, Pletcher MJ, Olgin JE, Grandis DJ, et al. Assessment of Accelerometer-Based Physical Activity During the 2017-2018 California Wildfire Seasons. JAMA Network Open. 2020 Sep;3(9):e2018116. 
97. Doubleday A, Choe Y, Busch Isaksen TM, Errett NA. Urban bike and pedestrian activity impacts from wildfire smoke events in Seattle, WA. Journal of Transport \& Health. 2021 Jun;21:101033.

98. del Pozo Cruz B, Hartwig TB, Sanders T, Noetel M, Parker P, Antczak D, et al. The effects of the Australian bushfires on physical activity in children. Environment International. 2021 Jan; 146:106214.

99. Andela N, Morton DC, Giglio L, Chen Y, van der Werf GR, Kasibhatla PS, et al. A human-driven decline in global burned area. Science. 2017 Jun 30;356(6345):1356-62.

100. Tenero L, Piacentini G, Nosetti L, Gasperi E, Piazza M, Zaffanello M. Indoor/outdoor notvoluptuary-habit pollution and sleep-disordered breathing in children: a systematic review. Translational Pediatrics. 2017 Apr;6(2):104-10.

101. Mutlu GM, Peker Y. Air Pollution, Asthma, and Sleep Apnea: New Epidemiological Links? Annals of the American Thoracic Society. 2019 Mar;16(3):307-8.

102. Szyszkowicz M, Thomson EM, Colman I, Rowe BH. Ambient air pollution exposure and emergency department visits for substance abuse. PLOS ONE. 2018 Jun;13(6):e0199826.

103. Thilakaratne RA, Malig BJ, Basu R. Examining the relationship between ambient carbon monoxide, nitrogen dioxide, and mental health-related emergency department visits in California, USA. The Science of the Total Environment. 2020 Dec;746:140915.

104. Tran VV, Park D, Lee Y-C. Indoor Air Pollution, Related Human Diseases, and Recent Trends in the Control and Improvement of Indoor Air Quality. Int J Environ Res Public Health. 2020 Apr;17(8):2927.

105. Kankaria A, Nongkynrih B, Gupta SK. Indoor Air Pollution in India: Implications on Health and its Control. Indian Journal of Community Medicine : Official Publication of Indian Association of Preventive \& Social Medicine. 2014;39(4):203-7.

106. Schwarzenbach RP, Egli T, Hofstetter TB, von Gunten U, Wehrli B. Global Water Pollution and Human Health. Annual Review of Environment and Resources. 2010;35(1):109-36.

107. Brevik EC, Slaughter L, Singh BR, Steffan JJ, Collier D, Barnhart P, et al. Soil and Human Health: Current Status and Future Needs. Air, Soil and Water Research. 2020 Jan $1 ; 13: 1178622120934441$.

108. Stansfeld SA, Matheson MP. Noise pollution: non-auditory effects on health. British Medical Bulletin. 2003 Dec 1;68(1):243-57.

109. Kulp SA, Strauss BH. New elevation data triple estimates of global vulnerability to sea-level rise and coastal flooding. Nature Communications. 2019 Oct;10(1):4844.

110. Mimura N. Sea-level rise caused by climate change and its implications for society. Proceedings of the Japan Academy Series B, Physical and Biological Sciences. 2013;89(7):281301.

111. Taherkhani M, Vitousek S, Barnard PL, Frazer N, Anderson TR, Fletcher CH. Sea-level rise exponentially increases coastal flood frequency. Scientific Reports. 2020 Apr;10(1):6466.

112. Marsooli R, Lin N, Emanuel K, Feng K. Climate change exacerbates hurricane flood hazards along US Atlantic and Gulf Coasts in spatially varying patterns. Nature Communications. 2019 Aug;10(1):3785. 
113. Cauchi JP, Correa-Velez I, Bambrick H. Climate change, food security and health in Kiribati: a narrative review of the literature. Global Health Action. 2019 Jan;12(1):1603683.

114. Chowdhury MZI, Rahman M, Akter T, Akhter T, Ahmed A, Shovon MA, et al. Hypertension prevalence and its trend in Bangladesh: evidence from a systematic review and meta-analysis. Clinical Hypertension [Internet]. 2020 Dec [cited 2020 Aug 19];26(1). Available from: https://clinicalhypertension.biomedcentral.com/articles/10.1186/s40885-020-00143-1

115. Khan AE, Ireson A, Kovats S, Mojumder SK, Khusru A, Rahman A, et al. Drinking Water Salinity and Maternal Health in Coastal Bangladesh: Implications of Climate Change.

Environmental Health Perspectives. 2011 Sep;119(9):1328-32.

116. Shammi M, Rahman MM, Bondad SE, Bodrud-Doza M. Impacts of Salinity Intrusion in Community Health: A Review of Experiences on Drinking Water Sodium from Coastal Areas of Bangladesh. Healthcare. 2019 Mar;7(1):50.

117. Dannenberg AL, Frumkin H, Hess JJ, Ebi KL. Managed retreat as a strategy for climate change adaptation in small communities: public health implications. Climatic Change. 2019 Mar;153(1):1-14.

118. Asugeni J, MacLaren D, Massey PD, Speare R. Mental health issues from rising sea level in a remote coastal region of the Solomon Islands: current and future. Australasian Psychiatry. 2015 Dec;23(6_suppl):22-5.

119. Wynes S, Nicholas KA, Zhao J, Donner SD. Measuring what works: quantifying greenhouse gas emission reductions of behavioural interventions to reduce driving, meat consumption, and household energy use. Environmental Research Letters. 2018 Nov;13(11):113002.

120. Wicker P. The carbon footprint of active sport participants. Sport Management Review (Elsevier Science). 2019 Aug;22(4):513-26.

121. Gifford R. Environmental Psychology Matters. Annual Review of Psychology. 2014 Jan;65(1):541-79.

122. Aleksandrowicz L, Green R, Joy EJM, Smith P, Haines A. The Impacts of Dietary Change on Greenhouse Gas Emissions, Land Use, Water Use, and Health: A Systematic Review. Wiley AS, editor. PLOS ONE. 2016 Nov;11(11):e0165797.

123. Fresán U, Sabaté J. Vegetarian Diets: Planetary Health and Its Alignment with Human Health. Advances in Nutrition (Bethesda, Md). 2019;10(Suppl_4):S380-8.

124. Hallström E, Carlsson-Kanyama A, Börjesson P. Environmental impact of dietary change: a systematic review. Journal of Cleaner Production. 2015 Mar;91:1-11.

125. Willett W, Rockström J, Loken B, Springmann M, Lang T, Vermeulen S, et al. Food in the Anthropocene: the EAT-Lancet Commission on healthy diets from sustainable food systems. The Lancet. 2019 Feb;393(10170):447-92.

126. Springmann M, Clark M, Mason-D’Croz D, Wiebe K, Bodirsky BL, Lassaletta L, et al. Options for keeping the food system within environmental limits. Nature. 2018 Oct;562(7728):519-25.

127. Willits-Smith A, Aranda R, Heller MC, Rose D. Addressing the carbon footprint, healthfulness, and costs of self-selected diets in the USA: a population-based cross-sectional study. The Lancet Planetary Health. 2020 Mar;4(3):e98-106. 
128. Lindgren E, Harris F, Dangour AD, Gasparatos A, Hiramatsu M, Javadi F, et al. Sustainable food systems-a health perspective. Sustainability Science. 2018;13(6):1505-17.

129. Shaw C, Hales S, Howden-Chapman P, Edwards R. Health co-benefits of climate change mitigation policies in the transport sector. Nature Climate Change. 2014 Jun;4(6):427-33.

130. Nieuwenhuijsen MJ. Urban and transport planning pathways to carbon neutral, liveable and healthy cities; A review of the current evidence. Environ Int. 2020 Jul;140:105661.

131. Nieuwenhuijsen MJ, Khreis H. Car free cities: Pathway to healthy urban living. Environment International. 2016 Sep;94:251-62.

132. Commission E. Reducing CO2 emissions from passenger cars - before 2020. Climate Action European Commission [Internet]. 2016 [cited 2020 Aug 19]; Available from:

https://ec.europa.eu/clima/policies/transport/vehicles/cars_en

133. Agency UEP. U.S. Transportation Sector Greenhouse Gas EmissionsOffice of Transportation and Air Quality: 1990 - 2017. 2019. Report No.: EPA-420-F-19-047.

134. Keall MD, Shaw C, Chapman R, Howden-Chapman P. Reductions in carbon dioxide emissions from an intervention to promote cycling and walking: A case study from New Zealand. Transportation Research Part D: Transport and Environment. 2018 Dec;65:687-96.

135. Mrkajic V, Vukelic D, Mihajlov A. Reduction of CO 2 emission and non-environmental cobenefits of bicycle infrastructure provision: the case of the University of Novi Sad, Serbia. Renewable and Sustainable Energy Reviews. 2015 Sep;49:232-42.

136. Quam V, Rocklöv J, Quam M, Lucas R. Assessing Greenhouse Gas Emissions and Health CoBenefits: A Structured Review of Lifestyle-Related Climate Change Mitigation Strategies. International Journal of Environmental Research and Public Health. 2017 Apr;14(5):468.

137. European commission. Walking and cycling as transport modes [Internet]. Mobility and transport - European Commission. 2016 [cited 2021 Nov 15]. Available from:

https://ec.europa.eu/transport/road_safety/specialist/knowledge/pedestrians/pedestrians_and_cycli sts_unprotected_road_users/walking_and_cycling_as_transport_modes_en

138. Nisa CF, Bélanger JJ, Schumpe BM, Faller DG. Meta-analysis of randomised controlled trials testing behavioural interventions to promote household action on climate change. Nature Communications. 2019 Oct;10(1):4545.

139. Arnott B, Rehackova L, Errington L, Sniehotta FF, Roberts J, Araujo-Soares V. Efficacy of behavioural interventions for transport behaviour change: systematic review, meta-analysis and intervention coding. International Journal of Behavioral Nutrition and Physical Activity [Internet]. 2014 Dec [cited 2021 Mar 20];11(1). Available from:

http://ijbnpa.biomedcentral.com/articles/10.1186/s12966-014-0133-9

140. Maki A, Carrico AR, Raimi KT, Truelove HB, Araujo B, Yeung KL. Meta-analysis of proenvironmental behaviour spillover. Nature Sustainability. 2019 Apr;2(4):307-15.

141. Wynes S, Zhao J, Donner SD. How well do people understand the climate impact of individual actions? Climatic Change [Internet]. 2020 Aug [cited 2020 Aug 20]; Available from: https://doi.org/10.1007/s10584-020-02811-5

142. Mulrow J, Machaj K, Deanes J, Derrible S. The state of carbon footprint calculators: An evaluation of calculator design and user interaction features. Sustainable Production and Consumption. 2019 Apr;18:33-40. 
143. Onken LS, Carroll KM, Shoham V, Cuthbert BN, Riddle M. Reenvisioning Clinical Science: Unifying the Discipline to Improve the Public Health. Clin Psychol Sci. 2014 Jan 1;2(1):22-34.

144. Czajkowski SM, Powell LH, Adler N, Naar-King S, Reynolds KD, Hunter CM, et al. From Ideas to Efficacy: The ORBIT Model for Developing Behavioral Treatments for Chronic Diseases. Health Psychol. 2015 Oct;34(10):971-82.

145. Sheeran P, Klein WMP, Rothman AJ. Health Behavior Change: Moving from Observation to Intervention. Annual Review of Psychology. 2017;68(1):573-600.

146. Skivington K, Matthews L, Simpson SA, Craig P, Baird J, Blazeby JM, et al. A new framework for developing and evaluating complex interventions: update of Medical Research Council guidance. BMJ. 2021 Sep 30;374:n2061.

147. Evans GW. Projected Behavioral Impacts of Global Climate Change. Annual Review of Psychology. 2019;70(1):449-74.

148. Kirkpatrick SB. Disaster relief trials: perceptions of a disaster-themed bicycling event. Disaster Prevention and Management: An International Journal. 2019 Jun;28(3):386-400.

149. Akiyama T, Gregorio ER, Kobayashi J. Youth sports activity and young people's well-being after a disaster: a trial with the Mastery Approach to Coaching (MAC) in the Philippines. BMC research notes. 2018 Oct;11(1):747.

150. Wahl-Alexander Z, Sinelnikov OA. Using Physical Activity for Emotional Recovery After a Natural Disaster. Journal of Physical Education, Recreation \& Dance. 2013 Apr;84(4):23-8.

151. Hong T, Farley TA. Urban residents' priorities for neighborhood features. A survey of New Orleans residents after Hurricane Katrina. American Journal of Preventive Medicine. 2008 Apr;34(4):353-6.

152. Purgato M, Richards J, Prina E, Kip A, Del Piccolo L, Michencigh G, et al. Efficacy of physical activity interventions on psychological outcomes in refugee, asylum seeker and migrant populations: A systematic review and meta-analysis. Psychology of Sport and Exercise. 2021 May;54:101901.

153. Xu C, Kohler TA, Lenton TM, Svenning J-C, Scheffer M. Future of the human climate niche. Proceedings of the National Academy of Sciences. 2020 May;117(21):11350-5.

154. Rigaud KK, de Sherbinin A, Jones B, Bergmann J, Clement V, Ober K, et al. Groundswell: Preparing for Internal Climate Migration [Internet]. Washington, DC: World Bank; 2018 Mar [cited 2021 Nov 15]. Available from: https://openknowledge.worldbank.org/handle/10986/29461

155. Stern N. The Economics of Climate Change: The Stern Review [Internet]. Cambridge: Cambridge University Press; 2007 [cited 2020 Aug 19]. Available from: https://www.cambridge.org/core/books/economics-of-climatechange/A1E0BBF2F0ED8E2E4142A9C878052204

156. Spaaij R, Broerse J, Oxford S, Luguetti C, McLachlan F, McDonald B, et al. Sport, Refugees, and Forced Migration: A Critical Review of the Literature. Frontiers in Sports and Active Living [Internet]. 2019 Oct [cited 2021 Jan 27];1. Available from: https://www.frontiersin.org/article/10.3389/fspor.2019.00047/full

157. Clinton N, Stuhlmacher M, Miles A, Uludere Aragon N, Wagner M, Georgescu M, et al. A Global Geospatial Ecosystem Services Estimate of Urban Agriculture. Earth's Future. 2018 Jan;6(1):40-60. 
158. Bhavani RV, Gopinath R. The COVID19 pandemic crisis and the relevance of a farm-systemfor-nutrition approach. Food Security. 2020 Aug;12(4):881-4.

159. Barthel S, Isendahl C. Urban gardens, agriculture, and water management: Sources of resilience for long-term food security in cities. Ecological Economics. 2013 Feb 1;86:224-34.

160. Litt JS, Soobader M-J, Turbin MS, Hale JW, Buchenau M, Marshall JA. The influence of social involvement, neighborhood aesthetics, and community garden participation on fruit and vegetable consumption. American Journal of Public Health. 2011 Aug;101(8):1466-73.

161. Litt JS, Lambert JR, Glueck DH. Gardening and age-related weight gain: Results from a cross-sectional survey of Denver residents. Preventive Medicine Reports. 2017 Dec;8:221-5.

162. Tharrey M, Perignon M, Scheromm P, Mejean C, Darmon N. Does participating in community gardens promote sustainable lifestyles in urban settings? Design and protocol of the JArDinS study. BMC Public Health. 2019 May 17;19(1):589.

163. Chen, Wang X, Thatcher M, Barnett G, Kachenko A, Prince R. Urban vegetation for reducing heat related mortality. Environmental Pollution (Barking, Essex: 1987). 2014 Sep;192:275-84.

164. Alaimo K, Beavers AW, Crawford C, Snyder EH, Litt JS. Amplifying Health Through Community Gardens: A Framework for Advancing Multicomponent, Behaviorally Based Neighborhood Interventions. Current Environmental Health Reports. 2016;3(3):302-12.

165. Gustavsson J, Cederberg C, Sonesson U. Global food losses and food waste: extent, causes and prevention; study conducted for the International Congress Save Food! at Interpack 2011, [16 - 17 May], Düsseldorf, Germany. Rome: Food and Agriculture Organization of the United Nations; 2011.

166. Bendell J, Read R. Deep Adaptation: Navigating the Realities of Climate Chaos. Cambridge, UK ; Medford, MA: Polity Press; 2021.

167. Servigne P, Stevens R, Brown A. How Everything Can Collapse: A Manual for Our Times. Cambridge, UK ; Medford, MA: Polity Press; 2020.

168. Bardi U. Before the Collapse: A Guide to the Other Side of Growth [Internet]. Springer International Publishing; 2020 [cited 2020 Oct 8]. Available from: https://www.springer.com/gp/book/9783030290375

169. Selby J, Dahi OS, Fröhlich C, Hulme M. Climate change and the Syrian civil war revisited. Political Geography. 2017 Sep 1;60:232-44.

170. Linke AM, Ruether B. Weather, wheat, and war: Security implications of climate variability for conflict in Syria. Journal of Peace Research. 2021 Jan 1;58(1):114-31.

171. Ash K, Obradovich N. Climatic Stress, Internal Migration, and Syrian Civil War Onset. Journal of Conflict Resolution. 2020 Jan 1;64(1):3-31.

172. Clark MA, Springmann M, Hill J, Tilman D. Multiple health and environmental impacts of foods. Proceedings of the National Academy of Sciences. 2019 Nov;116(46):23357-62.

173. Warner KE. Global warming comes to tobacco control. Tobacco Control. 2013 Sep;22(5):289-90.

174. Lecours N, Almeida GEG, Abdallah JM, Novotny TE. Environmental health impacts of tobacco farming: a review of the literature. Tobacco Control. 2012 Mar;21(2):191-6. 
175. Bjørnarå HB, Torstveit MK, Stea TH, Bere E. Is there such a thing as sustainable physical activity? Scandinavian Journal of Medicine \& Science in Sports. 2017 Mar;27(3):366-72.

176. Rosa CD, Collado S. Enhancing Nature Conservation and Health: Changing the Focus to Active Pro-environmental Behaviours. Psychological Studies. 2020 Mar;65(1):9-15.

177. Burlingame BA, Dernini S, Nations F and AO of the U, International B, editors. Sustainable diets and biodiversity: directions and solutions for policy, research and action. Rome: FAO; 2012.

178. Sabaté J, Jehi T. Chapter 10 - Determinants of sustainable diets. In: Sabaté J, editor. Environmental Nutrition [Internet]. Academic Press; 2019 [cited 2021 Nov 15]. p. 181-96. Available from: https://www.sciencedirect.com/science/article/pii/B9780128116609000126

179. Smith AJB, Tennison I, Roberts I, Cairns J, Free C. The carbon footprint of behavioural support services for smoking cessation. Tobacco Control. 2013 Sep;22(5):302-7.

180. Adshead F, Salman RA-S, Aumonier S, Collins M, Hood K, McNamara C, et al. A strategy to reduce the carbon footprint of clinical trials. The Lancet. 2021 Jul 24;398(10297):281-2.

181. Bernard, Ivers H, Savard M-H, Savard J. A longitudinal examination of the interrelationships between multiple health behaviors in cancer patients. Journal of Applied Biobehavioral Research. 2019;24(3):e12168.

182. Chevance G, Golaszewski NM, Baretta D, Hekler EB, Larsen BA, Patrick K, et al. Modelling multiple health behavior change with network analyses: results from a one-year study conducted among overweight and obese adults. Journal of Behavioral Medicine. 2020 Apr; 43(2):254-261.

183. Fisher EB, Fitzgibbon ML, Glasgow RE, Haire-Joshu D, Hayman LL, Kaplan RM, et al. Behavior matters. American Journal of Preventive Medicine. 2011 May;40(5):e15-30.

184. Fisher EB, Cameron LD, Christensen AJ, Ehlert U, Guo Y, Oldenburg B, et al. Introduction. In: Fisher EB, Cameron LD, Christensen AJ, Ehlert U, Guo Y, Oldenburg B, et al., editors. Principles and Concepts of Behavioral Medicine [Internet]. New York, NY: Springer New York; 2018 [cited 2020 Aug 5]. p. 3-30. Available from: http://link.springer.com/10.1007/978-0-38793826-4_1

185. Michie S, van Stralen MM, West R. The behaviour change wheel: A new method for characterising and designing behaviour change interventions. Implementation Science. $2011 \mathrm{Apr}$ $23 ; 6(1): 42$.

186. What is RE-AIM? - RE-AIM [Internet]. [cited 2021 Nov 15]. Available from: https://reaim.org/learn/what-is-re-aim/

187. Kok G, Gottlieb NH, Peters G-JY, Mullen PD, Parcel GS, Ruiter RAC, et al. A taxonomy of behaviour change methods: an Intervention Mapping approach. Health Psychology Review. 2016 Jul 2;10(3):297-312.

188. Knittle K, Heino M, Marques MM, Stenius M, Beattie M, Ehbrecht F, et al. The compendium of self-enactable techniques to change and self-manage motivation and behaviour v.1.0. Nature Human Behaviour. 2020 Feb;4(2):215-23.

189. Sorrell S, Gatersleben B, Druckman A. The limits of energy sufficiency: A review of the evidence for rebound effects and negative spillovers from behavioural change. Energy Research \& Social Science. 2020 Jun;64:101439. 
190. Oswald Y, Owen A, Steinberger JK. Large inequality in international and intranational energy footprints between income groups and across consumption categories. Nature Energy. 2020 Mar;5(3):231-9.

191. Song K, Qu S, Taiebat M, Liang S, Xu M. Scale, distribution and variations of global greenhouse gas emissions driven by U.S. households. Environment International. 2019 Dec;133:105137.

192. Butler CD. Sounding the Alarm: Health in the Anthropocene. International Journal of Environmental Research and Public Health. 2016 Jul;13(7):665.

193. Karner A, Hondula DM, Vanos JK. Heat exposure during non-motorized travel: Implications for transportation policy under climate change. Journal of Transport \& Health. 2015 Dec;2(4):451-9.

194. Halperin D. Environmental noise and sleep disturbances: A threat to health? Sleep Science. 2014 Dec 1;7(4):209-12.

195. Barbier EB, Hochard JP. The Impacts of Climate Change on the Poor in Disadvantaged Regions. Review of Environmental Economics and Policy. 2018 Feb;12(1):26-47.

196. den Elzen MGJ, Olivier JGJ, Höhne N, Janssens-Maenhout G. Countries' contributions to climate change: effect of accounting for all greenhouse gases, recent trends, basic needs and technological progress. Climatic Change. 2013 Nov;121(2):397-412.

197. Hubacek K, Baiocchi G, Feng K, Muñoz Castillo R, Sun L, Xue J. Global carbon inequality. Energy, Ecology and Environment. 2017 Dec;2(6):361-9.

198. Dugat C, Soyeux A. Doing your fair share for the climate? The power and responsibility of individuals businesses and the state in the fight against climate change: A french case study [Internet]. Available from: https://www.carbone4.com/wp-content/uploads/2019/11/Doing-yourfair-share-for-the-climate-Carbone-4.pdf

199. Shedding light on energy on the EU: Where does our energy come from? [Internet]. Shedding light on energy on the EU. [cited 2021 Nov 15]. Available from: https://ec.europa.eu/eurostat/cache/infographs/energy/bloc-2a.html

200. Newell P, Twena M, Daley F. Scaling behaviour change for a 1.5-degree world: challenges and opportunities. Global Sustainability [Internet]. 2021 ed [cited 2021 Nov 15];4. Available from: https://www.cambridge.org/core/journals/global-sustainability/article/scaling-behaviourchange-for-a-15-degree-world-challenges-andopportunities/C3F274E421D45486833FA311659A45F9

201. Watts N, Amann M, Arnell N, Ayeb-Karlsson S, Beagley J, Belesova K, et al. The 2020 report of The Lancet Countdown on health and climate change: responding to converging crises. The Lancet. 2021 Jan;397(10269):129-70.

202. Watts N, Amann M, Arnell N, Ayeb-Karlsson S, Belesova K, Boykoff M, et al. The 2019 report of The Lancet Countdown on health and climate change: ensuring that the health of a child born today is not defined by a changing climate. The Lancet. 2019 Nov;394(10211).

203. Thiery W, Lange S, Rogelj J, Schleussner C-F, Gudmundsson L, Seneviratne SI, et al. Intergenerational inequities in exposure to climate extremes. Science. 2021 Oct 8;374(6564):15860 . 
204. Jacquet J, Hagel K, Hauert C, Marotzke J, Röhl T, Milinski M. Intra- and intergenerational discounting in the climate game. Nature Climate Change. 2013 Dec;3(12):1025-8.

205. Anderson K, Broderick JF, Stoddard I. A factor of two: how the mitigation plans of 'climate progressive' nations fall far short of Paris-compliant pathways. Climate Policy. 2020 May;0(0):115.

206. Sorensen C, Murray V, Lemery J, Balbus J. Climate change and women's health: Impacts and policy directions. PLoS Medicine [Internet]. 2018 Jul [cited 2021 Feb 12];15(7). Available from: https://www.ncbi.nlm.nih.gov/pmc/articles/PMC6038986/

207. Smith JN, van Daalen KR, Venkatraman R. Climate change and its potential impact on menopausal hot flashes: a commentary. Menopause. 2020 Jul;27(7):816-7.

208. Canelón SP, Boland MR. A Systematic Literature Review of Factors Affecting the Timing of Menarche: The Potential for Climate Change to Impact Women's Health. International Journal of Environmental Research and Public Health. 2020 Jan;17(5):1703.

209. Kennedy J, King L. The political economy of farmers' suicides in India: indebted cash-crop farmers with marginal landholdings explain state-level variation in suicide rates. Globalization and Health. 2014 Mar;10:16.

210. Heino MTJ, Knittle K, Noone C, Hasselman F, Hankonen N. Studying Behaviour Change Mechanisms under Complexity. Behavioral Sciences. 2021 May;11(5):77.

211. Prochaska JJ, Nigg CR, Spring B, Velicer WF, Prochaska JO. The benefits and challenges of multiple health behavior change in research and in practice. Prev Med. 2010 Feb;50(1-2):26-9.

212. Geller K, Lippke S, Nigg CR. Future directions of multiple behavior change research. J Behav Med. 2017 Feb;40(1):194-202.

213. Sniehotta FF, Araújo-Soares V, Brown J, Kelly MP, Michie S, West R. Complex systems and individual-level approaches to population health: a false dichotomy? The Lancet Public Health. 2017 Sep;2(9):e396-7.

214. Schill C, Anderies JM, Lindahl T, Folke C, Polasky S, Cárdenas JC, et al. A more dynamic understanding of human behaviour for the Anthropocene. Nature Sustainability. 2019 Dec;2(12):1075-82.

215. Maniates MF. Individualization: Plant a Tree, Buy a Bike, Save the World? Global Environmental Politics. 2001 Aug;1(3):31-52.

216. Firth JA, Albery GF, Beck KB, Jarić I, Spurgin LG, Sheldon BC, et al. Analysing the Social Spread of Behaviour: Integrating Complex Contagions into Network Based Diffusions. arXiv:201208925 [cs, q-bio] [Internet]. 2020 Dec [cited 2021 Feb 12]; Available from: http://arxiv.org/abs/2012.08925

217. Kaaronen RO, Strelkovskii N. Cultural Evolution of Sustainable Behaviors: Proenvironmental Tipping Points in an Agent-Based Model. One Earth. 2020 Jan 24;2(1):85-97.

218. Gallagher R, Appenzeller T. Beyond Reductionism. Science. 1999 Apr;284(5411):79-79.

219. Van Vuuren DP, Bijl DL, Bogaart P, Stehfest E, Biemans H, Dekker SC, et al. Integrated scenarios to support analysis of the food-energy-water nexus. Nature Sustainability. 2019 Dec;2(12):1132-41. 
220. Xu J, Zhou J, Luo P, Mao D, Xu W, Nima Q, et al. Associations of long-term exposure to ambient air pollution and physical activity with insomnia in Chinese adults. Sci Total Environ. 2021 Oct 20;792:148197.

221. Riley WT, Rivera DE, Atienza AA, Nilsen W, Allison SM, Mermelstein R. Health behavior models in the age of mobile interventions: are our theories up to the task? Transl Behav Med. 2011 Mar 1;1(1):53-71.

222. Hekler EB, Michie S, Pavel M, Rivera DE, Collins LM, Jimison HB, et al. Advancing Models and Theories for Digital Behavior Change Interventions. American Journal of Preventive Medicine. 2016 Nov 1;51(5):825-32.

223. Taylor JC, Allman-Farinelli M, Chen J, Gauglitz JM, Hamideh D, Jankowska MM, et al. Perspective: A Framework for Addressing Dynamic Food Consumption Processes. Advances in Nutrition. 2022 Jan 6;nmab156.

224. Resnicow K, Page SE. Embracing Chaos and Complexity: A Quantum Change for Public Health. Am J Public Health. 2008 Aug;98(8):1382-9.

225. Zywert K, Quilley S. Health in the Anthropocene: Living Well on a Finite Planet. University of Toronto Press; 2020.

226. Sridhar K. Sustainability - "enough for all forever." International Journal of Business Excellence. 2014;7(4):454. 
Figure 1. Illustration of the "great acceleration", adapted from [1].
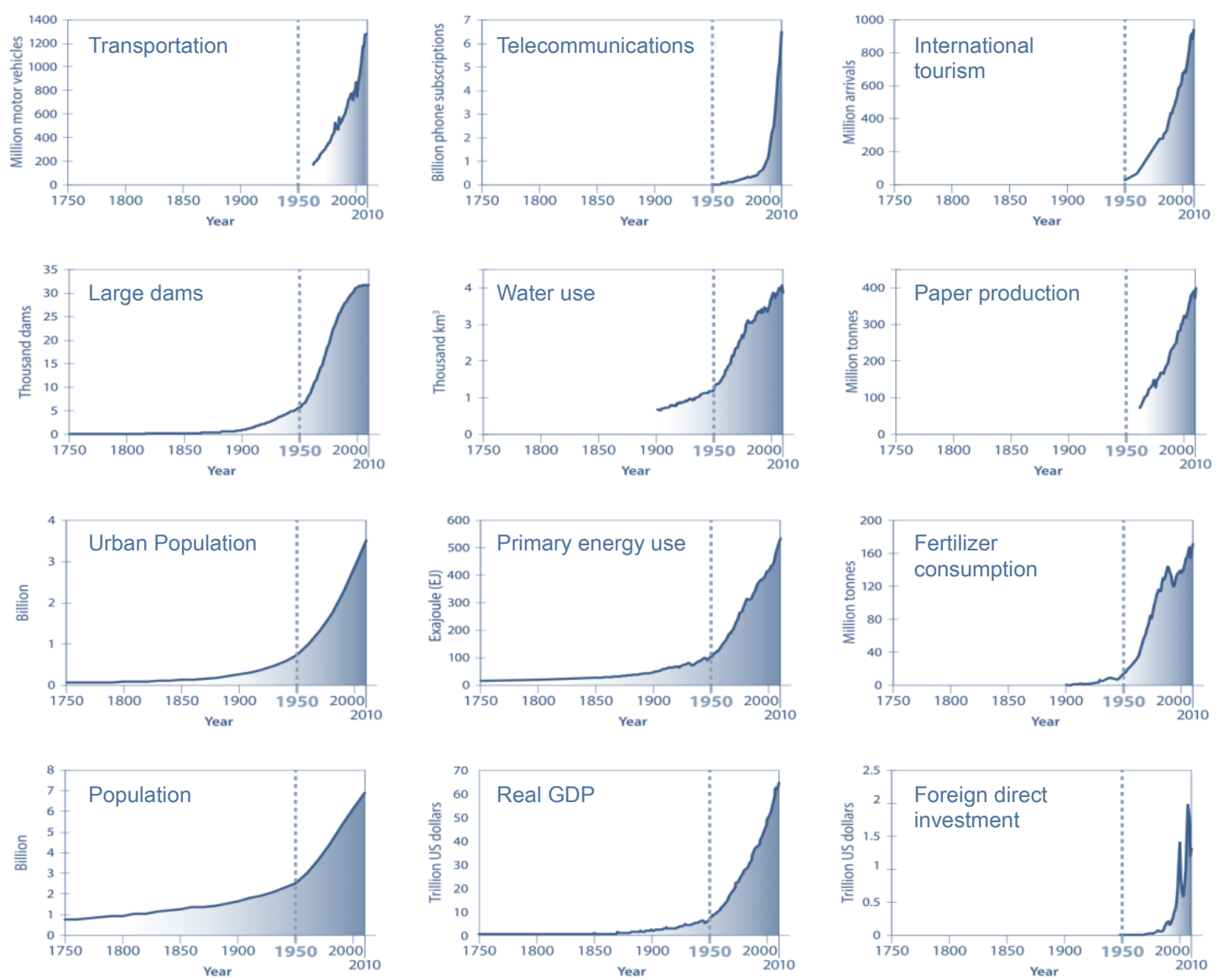

Note. X-axes represent time between the years 1750 and 2010; y-axes represent units in the relevant metric for each graph; vertical dashed lines represent the theorized beginning of the great acceleration. 
Figure 2. The Climate Change and Health Behaviors Feedback Loops Model

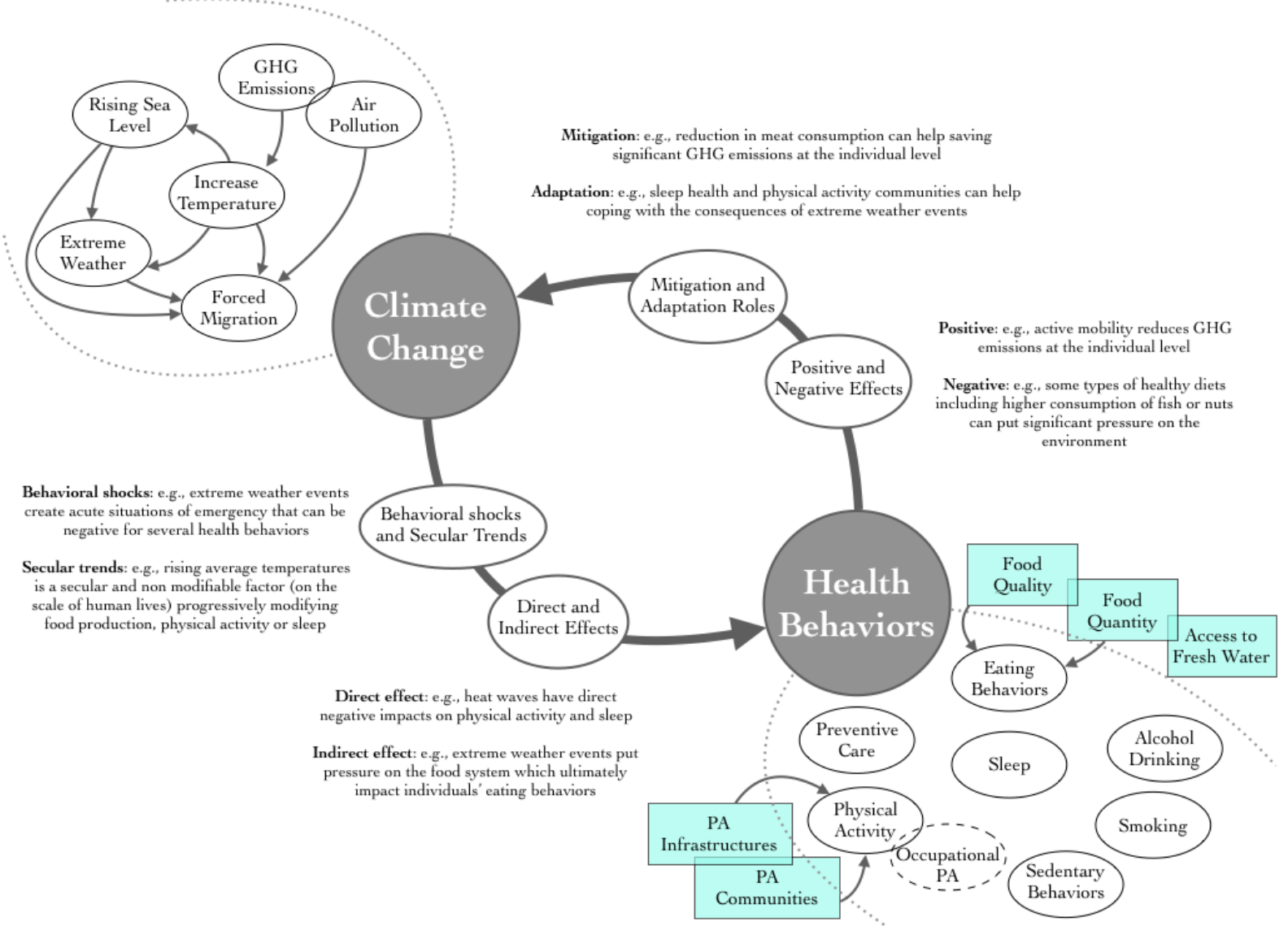

Note. PA = physical activity; the category "eating behaviors" refers here to the different behavioral sub-components identified in the literature review, such as the quantity and quality/type of food consumed by an individual; individual eating behaviors are influenced by structural factors related to food quantity and quality also named food production and security in the present review. GHG emissions and air pollution circles are intricated because GHGs are a type of air pollution. See the Figure description in section 3 for further details. See https://osf.io/pb8vc/ for an earlier version of this figure including individual associations between health behaviors and climate change outcomes. 
Table 1. Summary of the section 1: Impacts of climate change on health behaviors.

\begin{tabular}{|c|c|c|c|c|c|c|}
\hline & $\begin{array}{l}\text { Eating behaviors } \\
\text { and the food system }\end{array}$ & $\begin{array}{l}\text { Physical activity and } \\
\text { sedentary behaviors }\end{array}$ & Sleep & Substance use & Preventive care & Water consumption \\
\hline Rising temperatures & $\begin{array}{l}\text { Potential reduction in } \\
\text { the nutritional quality of } \\
\text { the food and its } \\
\text { availability, which } \\
\text { ultimately impacts } \\
\text { individual eating } \\
\text { behaviors (via } \\
\text { accessibility and } \\
\text { increase in prices) }\end{array}$ & $\begin{array}{l}\text { Complex, non-linear, } \\
\text { effect being highly } \\
\text { context dependent at the } \\
\text { world scale; specific } \\
\text { threat for occupational } \\
\text { activities and in } \\
\text { particular outdoor } \\
\text { workers }\end{array}$ & $\begin{array}{l}\text { Likely to amplify sleep } \\
\text { disturbances and } \\
\text { obstructive sleep apnea, } \\
\text { particularly in elderly, } \\
\text { low-income populations } \\
\text { and other vulnerable } \\
\text { groups }\end{array}$ & $\begin{array}{l}\text { Few studies available } \\
\text { and mixed findings }\end{array}$ & $\begin{array}{l}\text { Effects mediated by } \\
\text { extreme weather events; } \\
\text { see below }\end{array}$ & $\begin{array}{l}\text { Effects mediated by } \\
\text { rising sea level; see } \\
\text { below }\end{array}$ \\
\hline $\begin{array}{c}\text { Extreme weather } \\
\text { events }\end{array}$ & $\begin{array}{l}\text { Harm agricultural } \\
\text { production and threaten } \\
\text { food supply-chain; } \\
\text { might be associated } \\
\text { with unhealthy eating } \\
\text { behaviors through } \\
\text { mental health issues }\end{array}$ & $\begin{array}{l}\text { Direct negative effect } \\
\text { through the } \\
\text { deterioration of sport } \\
\text { and physical activity } \\
\text { facilities and indirect } \\
\text { negative effect through } \\
\text { acute stress disorders }\end{array}$ & $\begin{array}{l}\text { Negative impact on } \\
\text { sleep that can be } \\
\text { mediated by mental } \\
\text { health issues such as } \\
\text { greater post-disaster } \\
\text { states of fear or anxiety }\end{array}$ & $\begin{array}{l}\text { Few studies available } \\
\text { and mixed findings }\end{array}$ & $\begin{array}{l}\text { Negative impact on } \\
\text { medication adherence, } \\
\text { and preventive care (via } \\
\text { health systems } \\
\text { breakdown) }\end{array}$ & $\begin{array}{l}\text { Can disrupt and } \\
\text { contaminate water } \\
\text { supplies (e.g., via } \\
\text { damaged drinking water } \\
\text { wells), thus impacting } \\
\text { fresh water accessibility } \\
\text { and consumption }\end{array}$ \\
\hline Air pollution & $\begin{array}{l}\text { Can accumulate in the } \\
\text { food chain and } \\
\text { potentially reduces } \\
\text { worker productivity in } \\
\text { the food sector; might } \\
\text { also be associated to } \\
\text { unhealthy food choices }\end{array}$ & $\begin{array}{l}\text { Negative effect on } \\
\text { physical activity, } \\
\text { (particularly active } \\
\text { transportation) and } \\
\text { positively associated } \\
\text { with sedentary } \\
\text { behaviors }\end{array}$ & $\begin{array}{l}\text { Potentially associated } \\
\text { with higher sleep } \\
\text { disturbances such as } \\
\text { snoring, sleep initiation } \\
\text { and maintenance and } \\
\text { sleep apnea }\end{array}$ & $\begin{array}{l}\text { Few studies available } \\
\text { and mixed findings }\end{array}$ & $\begin{array}{l}\text { Potential association not } \\
\text { mentioned in the present } \\
\text { review }\end{array}$ & $\begin{array}{l}\text { Potential association not } \\
\text { mentioned in the present } \\
\text { review }\end{array}$ \\
\hline Rising sea level & $\begin{array}{l}\text { Salt water intrusion into } \\
\text { ground water supplies } \\
\text { negatively impacts } \\
\text { crops yields and food } \\
\text { nutritional quality }\end{array}$ & $\begin{array}{l}\text { Can negatively interact } \\
\text { with extreme weather } \\
\text { events and strengthen } \\
\text { their direct negative } \\
\text { effects on physical } \\
\text { activity infrastructures }\end{array}$ & $\begin{array}{l}\text { Living in a zone } \\
\text { threatened by rising sea } \\
\text { level can be associated } \\
\text { with mental-health } \\
\text { mediated sleep issues }\end{array}$ & $\begin{array}{l}\text { Potential association not } \\
\text { mentioned in the present } \\
\text { review }\end{array}$ & $\begin{array}{l}\text { Negative impact on } \\
\text { preventive care (e.g., } \\
\text { toilets or latrines use) } \\
\text { has been observed } \\
\text { because of forced- } \\
\text { relocations }\end{array}$ & $\begin{array}{l}\text { Salt water intrusion } \\
\text { threatens access to safe } \\
\text { drinking water and } \\
\text { increase individual's } \\
\text { sodium consumption }\end{array}$ \\
\hline
\end{tabular}


Table 2. Summary of propositions for future research and actions relative to each section

\begin{tabular}{|c|c|}
\hline Sections & xample of research and actions needed \\
\hline $\begin{array}{l}\text { Climate change } \\
\text { effects on health } \\
\text { behaviors } \\
\text { (section } 1 \text { ) }\end{array}$ & $\begin{array}{l}\text { Develop and test a framework to guide future actions and better understand the mechanisms linking } \\
\text { climate change and health behaviors which would integrate notions such as: } \\
\text { - (i) the distinction between direct (e.g., temperatures and physical activity) and indirect (e.g., } \\
\text { climate impact on the food system that ultimately relates to behaviors) effects of climate } \\
\text { change on health behaviors; } \\
\text { - (ii) the distinction between secular trends in behavioral tendencies due to climate change } \\
\text { (e.g., rising temperatures) and short-term behavioral shocks (e.g., post-extreme weather } \\
\text { events situations); } \\
\text { (iii) using an experimental medicine approach, the identification and distinction between } \\
\text { individual (e.g., PTSD, heat stress) and structural (e.g., destruction of infrastructures) } \\
\text { mechanisms of the association between climate change and health behaviors. }\end{array}$ \\
\hline $\begin{array}{l}\text { Mitigation, } \\
\text { adaptation and } \\
\text { amplification role } \\
\text { of health behaviors } \\
\text { (section 2) }\end{array}$ & $\begin{array}{l}\text { When relevant, shifting priorities from the study of traditional behaviors (e.g., a volume of } \\
\text { physical activity) toward the promotion of a behavior with higher mitigation potential and } \\
\text { adaptive behaviors embodied in a climate change context; this includes, for example, the } \\
\text { promotion of involvement in community gardens, replacement of short motorized trips by } \\
\text { active transport, reduced food-waste and meat consumption, the utilization of physical } \\
\text { activity or sleep health as resilience factors post-extreme weather events. } \\
\text { - Develop research to change the determinants/correlates of these specific behaviors using, for } \\
\text { instance, well known frameworks such as the intervention mapping approach and key } \\
\text { behavior change principles like goals setting. } \\
\text { - Develop research to better account for the environmental impacts of behavioral medicine } \\
\text { interventions in addition to their effects on health outcomes (i.e., investigate the specific } \\
\text { environmental impact of behavioral interventions) and avoid intervention modalities with } \\
\text { high environmental impact. }\end{array}$ \\
\hline $\begin{array}{l}\text { Feedback loops } \\
\text { (section 3) }\end{array}$ & $\begin{array}{l}\text { Moving from a reductionist to a complex system approach by examining and modelling } \\
\text { multiple interactions, rebound effects and feedback loops between climate change and health } \\
\text { behaviors, instead of studying these outcomes in isolation (multiple behavior change } \\
\text { approaches could guide future work towards this specific question). }\end{array}$ \\
\hline $\begin{array}{l}\text { Perspective } \\
\text { (section 4) }\end{array}$ & $\begin{array}{l}\text { - Adopt a new definition of health behaviors embodied in the climate change and planetary } \\
\text { health context as a guiding reference for future actions in the field. } \\
\text { - Thinking and developing actions tailored to individuals' socio-economical situations, thus } \\
\text { identifying key priorities separately for high, middle and low incomes contexts, both within } \\
\text { and between countries, as well as at the inter-generational level and for women and men. } \\
\text { - Thinking the interactions between individuals' behaviors (top-down approach) and } \\
\text { collective/political actions (bottom-up) as complementary and mutually interacting, instead } \\
\text { of in opposition. }\end{array}$ \\
\hline
\end{tabular}

